\title{
Innovative solutions for enhancing the fire resistance of slim-floor
}

\section{beams: Thermal experiments}

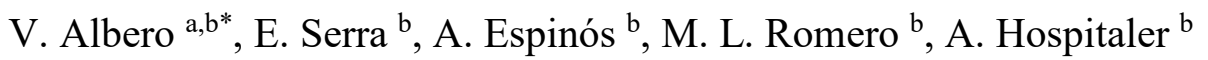 \\ ${ }^{a}$ Department of Mechanical Engineering and Construction, Universitat Jaume I, \\ Castellón, Spain \\ ${ }^{b}$ Instituto de Ciencia y Tecnología del Hormigón (ICITECH), Universitat Politècnica de \\ València, Valencia, Spain \\ *Corresponding author.e-mail address:valbero@uji.es
}

\begin{abstract}
Slim-floor beams have attracted the attention of designers in the last decades, owing to their ability for supporting intermediate loads without increasing the floor thickness. However, the behaviour of this type of beams at elevated temperatures has not been well understood yet. This paper presents the results of an experimental campaign carried out at the testing facilities of the Universitat Politècnica de València, Spain, where a series of slim-floor configurations were exposed to elevated temperatures into an electrical furnace. These tests had the novelty of considering different slim-floor beam typologies, as well as alternative ways for thermal protection, such as using intumescent coating, stainless steel or lightweight concrete into different cross-section parts. The test results were used to validate a finite element thermal model which allows for a detailed analysis of the cross-section thermal behaviour and the assessment of different ways to improve the slim-floor beam fire performance. The temperature results were subsequently imported into a computer code developed by the authors where a non-linear procedure was applied to obtain the plastic bending capacity of the cross-section at elevated temperatures. These final results reveal the different thermal performance of the
\end{abstract}


Albero V, Serra E. Espinós A, Romero ML, Hospitaler A. Innovative solutions for enhancing the fire resistance of slim-

floor beams: Thermal experiments. Journal of Constructional Steel Research 2020; 165.

https://doi.org/10.1016/j.jcsr.2019.105897

analysed configurations and are used as a basis for providing design recommendations for future slim-floor developments.

Keywords: Steel-concrete composite beams, fire resistance, slim-floor beam, electric furnace, thermal experiments

\section{INTRODUCTION}

During the last decades, a number of solutions have emerged in the construction of steelconcrete composite beams, such as the so-called "slim-floor beams", which are fully integrated into the floor depth. Slim-floor beams have been widely used in both residential and industrial buildings. This type of beam presents several advantages such as the composite steel-concrete action -in case of placing shear studs- and the reduced thickness, which permits that the steel beam is totally embedded within the floor, allowing for the construction of floors with a flat lower face. This is an essential aspect which may facilitate the installation of under-floor technical equipment in industrial buildings or increase the free ceiling height in residential developments.

Apart from the previously detailed advantages, the slim-floor beam also shows a good fire performance, by being exposed to fire only from its lower face, while the lateral parts of the beam are embedded in the concrete. In turn, other composite beams. - i.e. downstand beams -, where the steel beam is placed beneath the floor concrete slab, are exposed to the elevated temperatures from three faces in the fire situation. Therefore, slim-floor beams present a promising behaviour in fire which has attracted the attention of researchers in the last years [1$5]$. 
Albero V, Serra E. Espinós A, Romero ML, Hospitaler A. Innovative solutions for enhancing the fire resistance of slimfloor beams: Thermal experiments. Journal of Constructional Steel Research 2020; 165. https://doi.org/10.1016/j.jcsr.2019.105897

Nowadays, there can be found in Europe many different slim-floor beam configurations that have been made available in the market by steel manufacturers -ArcelorMittal, Tata Steel, Peikko, etc.-. All these available typologies have in common that they are composed of a lower steel plate working in tension, which also supports the secondary steel or concrete slab element during the construction process, and a concrete part working in compression.

This work is focused on the most widely used slim-floor beam configurations in Europe, namely Shallow Floor Beam (SFB) and Integrated Floor Beam (IFB), see Fig. 1. These configurations are made up of a commercial I-section welded to a bottom steel plate. In case of SFB, the I-section is entirely used, see Fig. 1b. In turn, the IFB is made of a half I-section welded directly to the bottom steel plate, see Fig. 1a. Thus, the SFB presents a double lower plate -the lower I-section flange welded to the bottom plate-, while the IFB is configured with a single bottom steel plate.

Regarding the fire behaviour of slim-floor beams, it is worth noting that due to the novelty of these composite beams, the current standards do not provide specific guidance to take into account the fire action in their mechanical behaviour. However, recent research work from Zaharia and Franssen [6] and Hanus et al. [7] has made available useful simplified models to predict the temperature development across the section members - bottom plate, profile web, reinforcing bars - when exposed to the standard ISO834 time-temperature curve.

Additionally, it should be highlighted that one of the key factors when determining the fire endurance of a structural member comes from the thermal behaviour of its cross-section when exposed to elevated temperatures. Related to this part of the analysis, the use of coating protections or innovative materials such as stainless steel or lightweight concrete may significantly influence the temperature evolution within the composite beam during the fire exposure, thus having an impact in improving its mechanical fire response. The innovative 
Albero V, Serra E. Espinós A, Romero ML, Hospitaler A. Innovative solutions for enhancing the fire resistance of slimfloor beams: Thermal experiments. Journal of Constructional Steel Research 2020; 165. https://doi.org/10.1016/j.jcsr.2019.105897

materials that are considered in this paper have been proved beneficial in other composite structural members $[8,9]$.

This paper presents the results of an experimental campaign of elevated temperature tests carried out at the testing facilities of the Universitat Politècnica de València, Spain, where a number of slim-floor configurations were subjected to thermal loads. These tests include SFB and IFB configurations, specimens protected with intumescent coating and specimens using stainless steel or lightweight concrete into different cross-section parts. The cross-sectional temperatures are recorded using more than 15 thermocouples in each specimen and the temperature results are subsequently used to calibrate a finite element (FE) thermal model. The developed FE model is revealed useful to achieve a better understanding of the cross-section thermal behaviour. Finally, the obtained temperatures are imported into a Matlab code developed by the authors where a non-linear plastic bending capacity analysis is carried out, allowing for the comparison of the mechanical response of the different configurations and the performance of the different protection strategies proposed. This comparison allows the authors to provide useful design recommendations to find the best strategies for enhancing the bending capacity of slim-floor beams in the fire situation, using innovative cross-section configurations that include materials with a potential to be used as fire-retardants, such as lightweight concrete or stainless steel.

\section{EXPERIMENTAL CAMPAIGN}

\subsection{Design of specimens}

The experimental campaign presented in this work was focused on the slim-floor beam thermal behaviour at elevated temperatures. The experiments presented hereafter were developed to understand the influence of different cross-section configurations in their thermal 
behaviour. Innovative solutions for lengthening the fire resistance like the usage of lightweight concrete aggregate at the concrete encasement or the usage of stainless steel at the steel bottom plate were tested.

Specifically, 8 experiments were carried out, see Table 1 . The specimens tested were classified in 4 different groups, each group was defined depending on the parameter or property under study. For instance, the first group -A1, A2 and A3 specimens- was focused on studying the influence of the cross-section geometry over their thermal behaviour. It should be noticed here that specimen A1 is used as a reference specimen for comparison, while the rest of the specimens were designed by modifying only one parameter from specimen A1, these variations were highlighted in bold letters in Table 1. In this way, the influence of each cross-section parameter variation can be analysed separately.

Specifically, A1 specimen was built as a SFB made up with an HEB200 steel profile welded to a $15 \times 360 \mathrm{~mm}$ bottom steel plate, see Fig. 2a. Specimen A2 differs from A1 on its bottom steel plate thickness $(20 \mathrm{~mm})$. In turn, specimen A3 was made as an IFB with $1 / 2$ IPE450 welded to a $30 \times 360 \mathrm{~mm}$ bottom steel plate, Fig. $2 \mathrm{~b}$. In this case, the steel elements of A3 were designed so as to have the same inertia as specimen A1 but with IFB configuration instead of SFB. Besides, the bottom plate thickness of specimen A3 $(30 \mathrm{~mm})$ equals the sum of the bottom plate thickness plus the lower flange thickness of specimen A1 $(15+15 \mathrm{~mm})$, see Fig. 2 . Moreover, it is important to notice that all specimens were tested with concrete encasement and in combination with hollow core slabs of $20 \mathrm{~cm}$ height (HCS20) as a secondary element for the floor system. Additionally, 2 reinforcing bars of $20 \mathrm{~mm}$ diameter and grade S500 (500 MPa yield strength) were also embedded in concrete with a $30 \mathrm{~mm}$ cover from the lower steel plate and placed at $40 \mathrm{~mm}$ distance to the profile web in all specimens, see Fig. 2. 
Albero V, Serra E. Espinós A, Romero ML, Hospitaler A. Innovative solutions for enhancing the fire resistance of slimfloor beams: Thermal experiments. Journal of Constructional Steel Research 2020; 165. https://doi.org/10.1016/j.jcsr.2019.105897

Differently from the previous group, in specimen A4 - group 2 - the concrete encasement was fabricated with lightweight aggregates. The difference in the thermal properties of the lightweight concrete at elevated temperatures, as compared with normal aggregate concrete, is included in EN 1994-1-2 [10] and consist mainly of lower values of conductivity and specific heat at elevated temperatures than normal aggregate concrete.

Group 3 - specimens A5, A6 and A7 - was defined to compare different ways to include thermal protections in the slim-floor cross-section by acting through the bottom steel plate. Specimen A5 is dimensionally equal to A1 but its bottom plate was made of austenitic stainless steel of grade 1.4301 (AISI 304). Recent research works [11], [12], [13] have shown the improved behaviour of stainless steel under fire conditions. Therefore, this specimen was designed to analyse the possible benefit of using this material at the bottom plate. Regarding specimen A6, it was externally protected by an intumescent coating of $1260 \mu \mathrm{m}$ thickness applied at the bottom plate. In turn, specimen A7 was internally protected by increasing the gap between the steel profile lower flange and the bottom plate. This gap increment was imposed by placing a wire $(1 \phi 5 \mathrm{~mm})$ between these two cross-section parts, see Fig. 3 .

Finally, group 4 consisted of an additional experiment (A8) where specimens A1 and A3 were tested together under the same heating conditions. The reason behind this final test comes from the interest in getting a test where both SFB and IFB specimens would be heated under exactly the same conditions. This fact will be further explained in the following sections but it can be anticipated here that, due to the furnace constraints, the heating condition of each experiment depends on the thermal inertia of the tested specimen.

Concerning the material properties, the steel members used in all specimens - i.e. steel profile and bottom plate - were grade $355 \mathrm{MPa}$, while the nominal compressive strength (cylindrical) of the concrete for the encasement was $30 \mathrm{MPa}$. Besides, the embedded reinforcing 
bars were grade S500 (500 MPa yield strength). In turn, the precast concrete hollow core slabs were manufactured with $45 \mathrm{MPa}$ nominal compressive strength (cylindrical).

\subsection{Test setup}

The experimental program presented in this paper was carried out at the testing facilities of Universitat Politècnica de València, Spain.

These thermal tests were developed using an electrical radiative furnace which consists of 4 electrical radiative panels $(4 \times 3 \mathrm{~kW})$. Each radiative panel is made of 4 ceramic blocks where the electric wires are embedded. The radiative panels were assembled creating a U-shape $(1020 \times 510 \times 1800 \mathrm{~mm})$ and the specimens to be tested were located on top of the heating panels covering the furnace, see Fig. 4 and Fig. 5. In this way, the tested slim-floor beams were exposed to elevated temperatures only from their lower surface, reproducing the real exposure conditions during a fire scenario. The rest of the furnace edges were protected with thermal insulation in order to minimize the heat loss.

In order to measure the temperature evolution, 4 plate thermocouples were placed inside the furnace, see Fig. 4. These plate thermocouples provided evidences about the temperature uniformity inside the furnace. It should be highlighted here that the radiative panels reach only $800^{\circ} \mathrm{C}$ and their electronic control does not allow to follow a predefined time-temperature curve. Indeed, each radiative panel can only be controlled by a long-term target temperature, which was established at its maximum value $\left(800^{\circ} \mathrm{C}\right)$ from the beginning of the test. Therefore, the power supply of the electric panels was maintained at $100 \%$ during the whole experiment. As a consequence, these tests cannot be considered as standard fire tests. In this sense, the temperature increment ratio $\left({ }^{\circ} \mathrm{C} / \mathrm{s}\right)$ into the furnace during each experiment depends on the thermal inertia of each tested specimen, which is part of the furnace boundary. 
Despite the constraints explained above, temperatures over $700{ }^{\circ} \mathrm{C}$ were reached at the exposed steel members. Thus, the long-term temperature field achieved in the cross-section during these tests can be considered to be of the same magnitude order than in a real fire scenario.

Despite the performed tests were not standard tests, they are useful for a qualitative comparison of the slim-floor beam thermal behaviour when the specimens are tested together (as in test A8). Besides, the rest of the experiments (A1 to A7) can also be used for validating the numerical model, as it will be described in Section 3. Once a numerical model is set up and verified, it can be subsequently used to perform quantitative comparisons under standard fire conditions.

The temperature field evolution along the slim-floor beam cross-section was registered in all the tests using up to 17 type $\mathrm{K}$ thermocouples placed at the middle section of the beam, see Fig. 6. Specifically, thermocouples TC1-TC2-TC2b recorded the temperature evolution of the steel bottom plate, while thermocouples TC3 to TC8 registered the temperature evolution along the main steel profile. Additionally, specific thermocouples were placed to obtain the temperature of the reinforcing bars (TC9-TC9b) and along the concrete encasement (c1-c6), see Fig. 6.

\subsection{Test results}

All the measured temperatures from the tests are displayed in Fig. 7 (in form of temperature-time curves) and Table 2 (for specific time periods). The thermocouple numbering

is the same for all the tested specimens. However, it should be noticed that the IFB configurations do not make use of thermocouples TC3 and TC4 because of the absence of lower flange, see Fig. 6. 
Albero V, Serra E. Espinós A, Romero ML, Hospitaler A. Innovative solutions for enhancing the fire resistance of slimfloor beams: Thermal experiments. Journal of Constructional Steel Research 2020; 165. https://doi.org/10.1016/j.jcsr.2019.105897

Likewise, Table 2 provides the measured temperatures after 30, 90 and 180 minutes of fire exposure, giving a more direct information about the thermocouple results which can be useful in design. Additionally, it should be mentioned that both Fig. 7 and Table 2 show the results from the numerical modelling, which will be detailed in following sections. Besides, the temperature distribution along the concrete depth is displayed in Fig. 8 after 90 and 180 minutes of the furnace heating exposure. The thermocouple measurements are depicted as a scatter plot, while the results from the numerical modelling are shown in dashed lines.

Having a closer look to the experimental results, it can be highlighted that the most significant differences with respect to the reference specimen -A1-were found in specimens A5 and A6. These specimens were protected from the temperature rise through different methods - using stainless steel and intumescent coating, respectively - and, as a consequence, showed an important reduction of the temperatures along the cross-section. Besides, it should be noticed that the lowest temperatures were obtained in specimen A6, which was protected by using intumescent coating, see Fig. 9.

In the case of test A5, with its bottom plate made up of stainless steel, the lower temperatures obtained may be explained by the lower emissivity of this material. Although this holds true when the specimen is exposed to high temperatures into an electric furnace, this effect should be deeply analyzed in real fires, where the fire produces soot that may cover the steel surfaces and thus modify the emissivity to consider into the heat transfer problem.

Finally, the results from test A8, displayed in Fig. 10, also show interesting information. In this case, both SFB and IFB configurations were tested together under the same fire exposure conditions. Thermocouples TC1 and TC4 for SFB and TC1 for IFB are displayed. It is important to underline that a significative difference, up to $100^{\circ} \mathrm{C}$, is shown between $\mathrm{TC} 1$ and TC4 temperature results in SFB. Therefore, it is clearly demonstrated that a thermal gap appears 
at the contact interface between the bottom plate and lower flange of SFB configuration, as it was already noticed in previous work [14]. In the case of the IFB configuration, thermocouple TC1 for the massive bottom plate $(15+15 \mathrm{~mm}$ thickness $)$ shows a temperature evolution which is halfway between that registered for thermocouples TC1 and TC4 in the SFB configuration.

\section{FINITE ELEMENT THERMAL MODEL}

This section presents the development of a finite element thermal model to reproduce the thermal behaviour of SFB and IFB composite beams when they are exposed to elevated temperatures. The results from the tests described in the previous section are used to validate this thermal model. Once validated, the thermal model will be used to predict the temperature field along the slim-floor cross-section when it is exposed to a standard time-temperature curve.

\subsection{Description of the finite element model}

The objective of this section is to develop a finite element (FE) model that allows solving the transient heat transfer problem. The fundamentals of the FE model are based on the resolution of the Fourier's equation:

$$
\nabla(\boldsymbol{k} \cdot \nabla \theta)=\rho c_{p} \frac{\partial \theta}{\partial t}
$$

The thermal conductivity $\boldsymbol{k}$ and the specific heat $c_{p}$ evolution for concrete and steel at elevated temperatures $(\theta)$ where adopted from EN 1994-1-2 Clause 3.3 [10]. Specifically, the upper limit was adopted for the concrete thermal conductivity and a 4\% moisture content was considered in the specific heat formulation. In turn, the corresponding values for lightweight concrete were used in the concrete encasement of the specimen A4. In the case of specimen A5 with a bottom plate made up of stainless steel, the values from EN 1993-1-2 Annex C [15] for the thermal properties at elevated temperatures were selected. 
Albero V, Serra E. Espinós A, Romero ML, Hospitaler A. Innovative solutions for enhancing the fire resistance of slim-

floor beams: Thermal experiments. Journal of Constructional Steel Research 2020; 165.

https://doi.org/10.1016/j.jcsr.2019.105897

The numerical resolution of the heat transfer problem was developed through the general purpose finite element modelling package ABAQUS [16]. A two-dimensional (2D) crosssection was modelled and meshed with four-noded quadrilateral elements with 2.5 and $5 \mathrm{~mm}$ maximum mesh size in case of steel and concrete parts, respectively, see Fig. 11. A finer mesh was used for steel in order to obtain an accurate temperature field prediction along the lower steel parts, having the highest influence over the mechanical behaviour of the composite beam in bending.

It is worth noting here that this work is focused on the behaviour of the slim-floor crosssection under elevated temperatures and the study of different ways to improve its fire performance. Therefore, only a 2D FE model is needed here, instead of other more sophisticated but time consuming 3D models that were previously developed by the authors [17].

Regarding the boundary conditions, heat radiation and convection were taken into account in both the exposed and unexposed surfaces. These heating conditions along the boundary elements can be mathematically defined as follows:

$$
-\boldsymbol{n} \cdot \boldsymbol{k} \cdot \nabla \theta=h\left(\theta-\theta_{\infty}\right)+F \cdot \varepsilon \cdot \sigma\left(\theta^{4}-\theta_{\infty}^{4}\right)
$$

where the convective coefficient $-h$ - at the exposed face is taken as $25 \mathrm{~W} / \mathrm{m}^{2} \mathrm{~K}$, while a value of $4 \mathrm{~W} / \mathrm{m}^{2} \mathrm{~K}$ is assumed at the unexposed face, as given in EN 1991-1-2 [18]. For the emissivity - $\varepsilon^{-}$, a value of 0.7 was used for concrete and normal steel at both the exposed and unexposed face. However, in the case of specimen A5 with stainless steel at the bottom plate, a lower value of 0.4 for the emissivity was used, as given in EN 1993-1-2 Clause 2.2 [15]. $\theta$ refers to the temperature at the steel or concrete element, while $\theta_{\infty}$ represents the fire action as a time-temperature curve and $\mathbf{n}$ represents the normal vector to the boundary facet.

Another important boundary condition accounted for in the model is the cavity radiation, which was imposed within the voids of the precast hollow core slabs, see Fig. 11 . This cavity 
Albero V, Serra E. Espinós A, Romero ML, Hospitaler A. Innovative solutions for enhancing the fire resistance of slimfloor beams: Thermal experiments. Journal of Constructional Steel Research 2020; 165. https://doi.org/10.1016/j.jcsr.2019.105897

radiation model allows for the flow of radiative heat between the facets of the elements lying on the void contour. $A B A Q U S$ computes automatically the view factor $F$ for each element facet depending on its geometry and relative position.

Contacts between the different steel and concrete parts were taken into account in the model. The presence of a thermal resistance at the interface between two layers of a multilayered solid is a well-known phenomenon [19]. No matter how thin the gap between the two contacting surfaces appears to be, it is a proved fact that even microscopically contact surfaces produce a thermal resistance that influences the result of the heat transfer problem.

In the particular case of this FE model, two different contact interfaces can be distinguished: the steel-steel contact between bottom plate and lower steel flange - in SFB and the steel-concrete contact between the steel members and concrete encasement. These contacts do not show the same behaviour. Indeed, it was noticed in previous works [14], [20], [21] that a thermal bow appears at the steel-steel contact between the bottom plate and lower flange that may cause the increase of the gap between these two elements at elevated temperatures. Therefore, different thermal conductance values were assumed for steel-steel and concrete-steel interfaces, see Fig. 11. Specifically, based on the results of a previous sensitivity study, a value of $250 \mathrm{~W} / \mathrm{m}^{2} \mathrm{~K}$ of thermal conductance was established for the concrete-steel interaction, while a value of $100 \mathrm{~W} / \mathrm{m}^{2} \mathrm{~K}$ was assumed at the steel-steel thermal gap between the bottom plate and the lower flange of the steel profile. Additionally, it should be noticed that in the case of the stainless steel bottom plate (specimen A5), the different emissivity of this material also interacts with the thermal conductance at the interface between the two steel members. As it was already found by other authors in composite members using this type of material [9], stainless steel reduces the heat flow between the contacting surfaces, thus decreasing the thermal conductance across the gap. In this work, a value of $25 \mathrm{~W} / \mathrm{m}^{2} \mathrm{~K}$ was used 
Albero V, Serra E. Espinós A, Romero ML, Hospitaler A. Innovative solutions for enhancing the fire resistance of slimfloor beams: Thermal experiments. Journal of Constructional Steel Research 2020; 165. https://doi.org/10.1016/j.jcsr.2019.105897

for the steel-steel contact interface when the bottom plate was made of stainless steel (specimen A5).

The modelling of specimen A6 deserves a specific description to clarify how the intumescent coating protection applied at the bottom plate was taken into account in the FE model. Previous work [22] concluded that the intumescent coating can be modelled on a simplified way by including an additional layer of finite elements along the coated surfaces. In this case, a single layer of four-noded quadrilateral elements was added at the exposed bottom plate surface, with a maximum finite element mesh size of $1.2 \mathrm{~mm}(1260 \mu \mathrm{m}$ thickness coating $)$. Reproducing the realistic expansion of the intumescent coating in a thermo-mechanical analysis may result in very high computing times. Instead, the authors have chosen a representative value of the thermal properties that allow for an accurate prediction of the temperature field of the protected specimens along the fire exposure time.

Previous studies on protected slim-floor beams with intumescent coating [22] calibrated the thermal properties of this material at elevated temperatures in order to deal with the heat transfer problem modelling issues. Specifically, a conductivity value of $\mathrm{k}=0.02 \mathrm{~W} / \mathrm{m} \cdot \mathrm{K}$; a density of $200 \mathrm{~kg} / \mathrm{m}^{3}$ and an specific heat of $1200 \mathrm{~J} / \mathrm{Kg} \cdot \mathrm{K}$ were considered in [22]. In this work, the given values - referred to as intumescent coating 'Model A' - were assumed, obtaining the results shown in Fig. 12 for the thermocouple TC1 of A6 specimen. It can be observed in Fig. 12 that 'Model A' does not follow the TC1 test results during the first minutes of fire exposure but it finally achieves the goal temperature near $400^{\circ} \mathrm{C}$. The reason of this behaviour was already noticed by other authors who analysed in depth the intumescent coating behaviour in fire [23]. Thus, using this model can only be considered accurate for temperatures above $400^{\circ}$ C. The reason of this deviation is due to the actual reaction of the intumescent coating at elevated temperatures causing its expansion and the consequent increase of its thickness, which 
is not constant during the fire exposure. Indeed, the intumescent coating reaction starts at $200^{\circ} \mathrm{C}$ and can be considered fully developed at $400^{\circ} \mathrm{C}$. This behaviour can be clearly observed in Fig. 12 ("TestA6-TC1") where it can be seen that the slope of the temperature evolution decreases dramatically when $\mathrm{TC} 1$ reaches $200^{\circ} \mathrm{C}$ and the intumescent coating starts to react. In order to reproduce this observed 'bilinear' behaviour, the thermal properties of the intumescent coating described above need to be modified.

It is well known that in this type of transient heat transfer problem, the main parameter which drives the temperature evolution along the material is the thermal diffusivity $(\alpha=\mathrm{k}$ $\left./\left(\rho \cdot c_{p}\right)\right)$. In order to accelerate the temperature evolution in the FE model during the first minutes of fire exposure, the thermal diffusivity should be increased. There are different ways to increase thermal diffusivity: increasing thermal conductivity; decreasing density or decreasing specific heat. In this case, the conductivity has been increased up to $0.2 \mathrm{~W} / \mathrm{m} \cdot \mathrm{K}$ for temperatures lower than $200^{\circ} \mathrm{C}$ and maintained in $0.02 \mathrm{~W} / \mathrm{m} \cdot \mathrm{K}$ for temperatures above $400^{\circ} \mathrm{C}$. The thermal conductivity between $200^{\circ} \mathrm{C}$ and $400^{\circ} \mathrm{C}$ can be interpolated between these two values. This model can be mathematically defined as follows:

$$
k(W / m \cdot K)=\left\{\begin{array}{cc}
0.2 & \theta<200^{\circ} C \\
0.2-\frac{0.18}{200}(\theta-200) & 200^{\circ} C<\theta<400^{\circ} C \\
0.02 & \theta>400^{\circ} C
\end{array}\right.
$$

This variation in the thermal model definition of the intumescent coating is here referred to as 'Model B' and reproduces the non-linear reaction of the intumescent coating when exposed to elevated temperatures. Fig. 12 proves that 'Model B' provides a more accurate representation of $\mathrm{TC} 1$ evolution than using 'Model A' in the FE modelling. 


\subsection{Validation of the finite element model}

Taking into account all the described modelling strategies and selected parameters, the developed FE model was validated by comparison against all the test results from the experimental campaign detailed in the previous section. The numerical model shows a good agreement with the test results, where the predictions are presented in Fig. 7 using dashed lines, in comparison with the experimental results plotted in solid lines. Table 2 presents also the particular values of the numerical predictions for specific fire exposure times, which can be used for the purpose of design. Additionally, the comparison between the numerically computed temperature profile along the concrete depth, for A1 specimen, and the thermocouple measurements after 90 and 180 minutes of the furnace heating exposure is shown in Fig. 8.

The direct comparison between experimental thermocouple measurements and numerical temperatures is plotted in Fig. 13. This comparison shows again the good agreement between the numerical model predictions and the experiment results, with a mean error value of 1.03 and a standard deviation of 0.14 .

\section{THERMO-MECHANICAL RESPONSE OF SLIM-FLOOR BEAMS UNDER STANDARD FIRE CONDITIONS}

Once the thermal model was validated, the next step was to compare the mechanical behaviour at elevated temperatures of the different tested specimens. It is important to recall here that due to the particular heating conditions of the furnace, the experiments described in Section 2 were exposed to unequal non-standard heating regimes. Therefore, the developed FE model appears as an important tool to reproduce the same standard heating conditions for all the test specimens. 
In order to perform this comparison under the same heating conditions, the FE model was used to simulate the thermal response of all the tested specimens, detailed in Table 1, under a standard ISO834 time-temperature curve. The results obtained from these analyses were the temperature evolution of all the nodes of the FE model $\left(\theta_{i}\right)$ along the slim-floor beam crosssection for all tested specimens.

Once the temperature evolution of all the nodes is obtained from the thermal analysis, the cross-section plastic bending resistance at elevated temperatures $\left(M_{p l, R d, \theta}\right)$ can be computed by using the equilibrium equations. Due to the non-linear mechanical behaviour of concrete and steel at elevated temperatures, the equilibrium equations should be computed by using an iterative incremental analysis:

$$
\left[\begin{array}{c}
\delta N_{R d, \theta} \\
\delta M_{p l, R d, \theta}
\end{array}\right]=\left[\begin{array}{ll}
E_{11} & E_{12} \\
E_{21} & E_{22}
\end{array}\right] \cdot\left[\begin{array}{c}
\delta \varepsilon_{0} \\
\delta \chi_{y}
\end{array}\right]
$$

where:

$$
E_{11}=\iint E_{\theta} d A ; E_{12}=E_{21}=\iint E_{\theta} y d A ; E_{22}=\iint E_{\theta} y^{2} d A
$$

In this case, the specimen is axially unrestrained and thus the external net axial force can be fixed as $\delta N_{R d, \theta}=0$. The strain in the reference point $\left(\varepsilon_{0}\right)$ and the curvature of the crosssection around the y-axis $\left(\chi_{y}\right)$ are increased gradually by applying an iterative process (see Fig. 14) until the equilibrium is reached, taking into account the non-linear behaviour of the materials at elevated temperatures $\left(E_{\theta}\right)$. Usually, the process for computing the cross-section plastic bending resistance is carried out on a simplified way by dividing the composite beam into different parts: the concrete in compression, the steel bottom plate in tension, the flange and web of the steel profile, etc. However, taking advantage of the available temperature evolution previously computed for all the nodes through the thermal FE model, the cross- 
Albero V, Serra E. Espinós A, Romero ML, Hospitaler A. Innovative solutions for enhancing the fire resistance of slimfloor beams: Thermal experiments. Journal of Constructional Steel Research 2020; 165. https://doi.org/10.1016/j.jcsr.2019.105897

section was subdivided into cells matching with the finite elements of the thermal model. This procedure was implemented into a specific Matlab [24] code developed by the authors.

The stiffness matrix can be computed more accurately by using a finer temperature field as follows:

$$
E_{11}=\sum E_{\theta, i} A_{i} ; E_{12}=E_{21}=\sum E_{\theta, i} y A_{i} ; E_{22}=\sum E_{\theta, i} y_{i}^{2} A_{i}
$$

The secant elastic modulus $\left(E_{\theta, i}\right)$ for each $i$-cell at temperature $\theta_{i}$ and under the pair $\left(\varepsilon_{0}, \chi_{y}\right)$, is obtained from the stress-strain model for concrete and steel at elevated temperatures, which are taken from EN 1994-1-2 [10] and EN 1993-1-2 [15], respectively. In the case of stainless steel, in order have the same comparison framework, the $0.2 \%$ proof strength at room temperature was assumed to be equal to the yield strength of the carbon steel used in the rest of specimens. The constitutive model for stainless steel at elevated temperatures was taken from EN 1993-1-2 [15] Annex C.

The thermal strains $\left(\varepsilon_{t h}\right)$ were taken into account for all the considered materials, using those models provided by EN 1994-1-2 [10]. The way to include this effect in the Matlab code was by substracting the thermal strains from the total strain before solving the equilibrium equations:

$$
\varepsilon_{\sigma}=\varepsilon-\varepsilon_{t h}
$$

However, as it was previously noticed, the composite beam was assumed as axially unrestrained. Therefore, thermal strains do not produce net external axial force. Thus, the thermal strains along the cross-section produce an internal stress field with null resultant force. However, null internal curvature $\left(\chi_{y}\right)$ generates non-zero bending moment due to the effect of the thermal strains $\left(\varepsilon_{t h}\right)$.

As it was explained above, the resolution process is non-linear. The incremental analysis procedure is performed by increasing the curvature $\left(\chi_{y}\right)$ until the maximum value of the 
Albero V, Serra E. Espinós A, Romero ML, Hospitaler A. Innovative solutions for enhancing the fire resistance of slimfloor beams: Thermal experiments. Journal of Constructional Steel Research 2020; 165. https://doi.org/10.1016/j.jcsr.2019.105897

bending moment is achieved or the stiffness matrix becomes singular. Following from this procedure, a non-linear $M-\chi$ curve is obtained for each specimen and fire exposure time.

Moreover, it should be noted that the theoretical plastic bending resistance analysis was computed taking into account the full composite action (Table 3) and also assuming no composite action (Table 4). The composite action in real situations depends on the amount of shear force that can be transferred between steel and concrete parts. Usually, this shear transfer is achieved partially through shear studs, which are placed between concrete and steel members. In any case, this work presents the extreme case analysis, composite and non-composite action, while the real situation will lay between the two, depending on the degree of shear transfer achieved. Additionally, it should be noted that the tensile strength of concrete was neglected in all cases. The results of the mechanical analysis for the different standard fire exposure times are presented in Fig. 15, Table 3 and Table 4. These tables also show the neutral line (NL) position, measured from the bottom reference line, when the maximum plastic bending moment is achieved. It can be observed, as expected, that the higher the fire exposure time, the lower the ultimate plastic bending moment achieved. Fig. 15 shows the evolution of the flexural capacity of the beams at elevated temperatures, taking into account full composite action, as a ratio of their elevated temperature plastic bending moment resistance over the bending resistance at room temperature for each specimen. In this plot, all the curves start from $(0,1)$ point - i.e. same normalized bending capacity at the start of fire exposure - so that the bending capacity evolution of the different specimens during the fire exposure can be directly compared.

From this figure, it can be seen that the superior behaviour in bending during fire is exhibited by specimen A5, which was externally protected with intumescent coating. It is followed by specimen A6, with its bottom plate made of stainless steel. The results from these two specimens reveal that the most effective solutions to improve the slim-floor beam fire 
Albero V, Serra E. Espinós A, Romero ML, Hospitaler A. Innovative solutions for enhancing the fire resistance of slimfloor beams: Thermal experiments. Journal of Constructional Steel Research 2020; 165. https://doi.org/10.1016/j.jcsr.2019.105897

resistance, are obtained by acting over the bottom plate protection. Other studied options, such as the usage of lightweight concrete encasement (A4) or the increase of the bottom plate thickness (A2) do not provide such a promising fire behaviour.

As far as IFB configuration is concerned (A3 specimen), Fig. 15 shows that the relative bending capacity of this specimen at elevated temperature remains slightly below that of the SFB configurations for the range between 30 and 120 minutes, recovering the same levels of capacity of the SFBs after 2 hours fire exposure. The reason of this behaviour comes from the beneficial effect of the previously mentioned thermal gap which appears between the bottom plate and the lower flange of the steel profile in the SFB configuration, which delays the temperature rise in the section as compared to IFB configurations. This finding reveals that the decrease of the fire resistance of SFB is lower during the first minutes of fire exposure, due to the beneficial effect of the thermal gap described in previous sections.

\section{DESIGN RECOMMENDATIONS AND CONCLUDING REMARKS}

The thermal response of different slim-floor configurations and fire protection strategies has been studied in detail in this paper, through the development of 8 electric furnace tests complemented with numerical simulations.

A sectional FE model has been developed and validated by comparison with the test results, with the potential to analyse the thermal behaviour of different slim-floor beam solutions. Additionally, a non-linear model to compute the plastic bending capacity of the slimfloor cross-section at elevated temperatures has also been developed, which has been used to evaluate and compare the performance of different slim-floor beam configurations under standard fire conditions.

From the performed analyses, some preliminary design recommendations for future developments in slim-floor beam applications can be given: 
- An effective way to improve the fire bending capacity of slim-floor composite beams consists of acting at the bottom steel plate through the use of materials that delay the temperature rise.

- There is a direct way to protect the slim-floor bottom plate by using an external protection based on intumescent coatings. This is the most effective technique to provide fire protection to the cross-section, but requires an accurate application and maintenance during the whole life cycle of the structure.

- In turn, there are other available options to internally protect the slim-floor beam against the fire action. The most effective one amongst these options consists of using stainless steel at the bottom plate. This material provides an improved fire performance, owing to its reduced emissivity and slower loss of strength at elevated temperatures. Moreover, the use of stainless steel also offers corrosion protection of the exposed side and a good aesthetic finishing. Despite its higher initial cost, this may be overcome by a more rational use of the materials in the composite section.

- The comparison between the mostly used slim-floor configurations (IFB and SFB) reveals that the SFB typology, with double bottom plate, shows a slightly better fire performance due to the thermal gap which appears between these two steel plates, providing a delay in the temperature increase of the lower crosssection parts.

\section{ACKNOWLEDGEMENTS}


Albero V, Serra E. Espinós A, Romero ML, Hospitaler A. Innovative solutions for enhancing the fire resistance of slim-

floor beams: Thermal experiments. Journal of Constructional Steel Research 2020; 165.

https://doi.org/10.1016/j.jcsr.2019.105897

The authors would like to express their sincere gratitude to the Spanish "Ministerio de Economía y Competitividad” for the help provided through the Project BIA2015-67192-R and to the European Union through the FEDER funds.

\section{REFERENCES}

1. Newman, G.M., Fire resistance of slim floor beams. Journal of Constructional Steel Research, 1995. 33(1-2): p. 87-100.

2. Kim, H.J., H.Y. Kim, and S.Y. Park, An experimental study on fire resistance of slim floor beam, in Applied Mechanics and Materials. 2011. p. 752-757.

3. Ma, Z. and P. Mäkeläinen, Structural behaviour of composite slim floor frames in fire conditions. Journal of Constructional Steel Research, 2006. 62(12): p. 1282-1289.

4. Ellobody, E., Nonlinear behaviour of unprotected composite slim floor steel beams exposed to different fire conditions. Thin-Walled Structures, 2011. 49(6): p. 762-771.

5. Romero, M.L., et al., Fire design of slim-floor beams. Stahlbau, 2019. 88(7): p. $665-674$.

6. Zaharia, R. and J.M. Franssen, Simple equations for the calculation of the temperature within the cross-section of slim floor beams under ISO Fire. Steel and Composite Structures, 2012. 13(2): p. 171-185.

7. Hanus, F., et al., Analytical methods for the prediction of fire resistance of "reinforced" slim floor beams, in EuroSteel 2017, E. Sohn, Editor. 2017: Copenhagen, Denmark.

8. Tao, Z., et al., Experimental and numerical investigation of concrete-filled stainless steel columns exposed to fire. Journal of Constructional Steel Research, 2016. 118: p. 120-134.

9. Han, L.-H., et al., Fire performance of concrete filled stainless steel tubular columns. Engineering Structures, 2013. 56: p. 165-181.

10. CEN, EN 1994-1-2, Eurocode 4: Design of composite steel and concrete structures. Part 1-2: General rules - Structural fire design. 2005, Comité Européen de Normalisation: Brussels, Belgium.

11. Gardner, L., et al., Elevated temperature material properties of stainless steel alloys. Journal of Constructional Steel Research, 2010. 66(5): p. 634-647.

12. Chen, J. and B. Young, Stress-strain curves for stainless steel at elevated temperatures. Engineering Structures, 2006. 28(2): p. 229-239. 
13. Renaud, C., RFS-04048 "Stainless Steel in Fire". WP 2: Composite members in fire. Final Report. 2007, CTICM.

14. Both, C., J.H.H. Fellinger, and L. Twilt, Shallow floor construction with deep composite deck: From fire tests to simple calculation rules. Heron, 1997. 42(3): p. 145-158.

15. CEN, EN 1993-1-2, Eurocode 3: Design steel structures. Part 1-2: General rules - Structural fire design. 2005, Comité Européen de Normalisation: Brussels, Belgium.

16. ABAQUS, Abaqus/Standard Version 6.14 User's Manual: Volumes I-III. Pawtucket, Rhode Island: Hibbit, Karlsson \& Sorensen, Inc, 2014.

17. Albero, V., et al., Numerical study on the flexural behaviour of slim-floor beams with hollow core slabs at elevated temperature. Engineering Structures, 2019. 180: p. 561-573.

18. CEN, EN 1991-1-2, Eurocode 1: Actions on structures. Part 1-2. General actions - actions on structures exposed to fire. 2002, Comité Européen de Normalisation: Brussels, Belgium.

19. Cengel, Y.A. and A.J. Ghajar, Heat and mass transfer: Fundamentals and Applications, ed. ed. 2014: McGraw-Hill.

20. Romero, M.L., et al., Fire design methods for slim-floor structures. Steel Construction, 2015. 8(2): p. 102-109.

21. Sharma, S., V.T. Vaddamani, and A. Agarwal, Insulation effect of the concrete slab-steel deck interface in fire conditions and its influence on the structural fire behavior of composite floor systems. Fire Safety Journal, 2019. 105: p. 79-91.

22. Alam, N., et al., Structural response of unprotected and protected slim floors in fire. Journal of Constructional Steel Research, 2018. 142: p. 44-54.

23. Li, G.Q., J. Han, and Y. Wang, Constant effective thermal conductivity of intumescent coatings: Analysis of experimental results. Vol. 35. 2017. 073490411769385.

24. MathWorks, MATLAB, R2016b, Editor. 2016: Natick, Massachusetts USA. 
Albero V, Serra E. Espinós A, Romero ML, Hospitaler A. Innovative solutions for enhancing the fire resistance of slimfloor beams: Thermal experiments. Journal of Constructional Steel Research 2020; 165. https://doi.org/10.1016/j.jcsr.2019.105897

a)

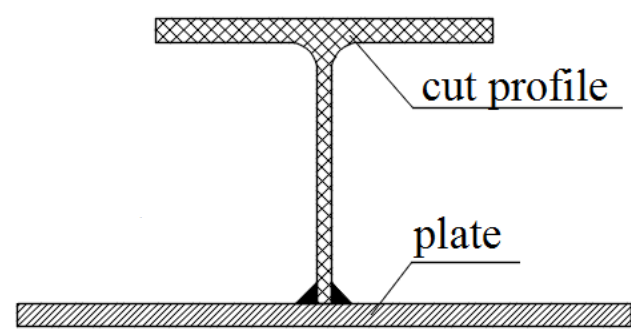

b)

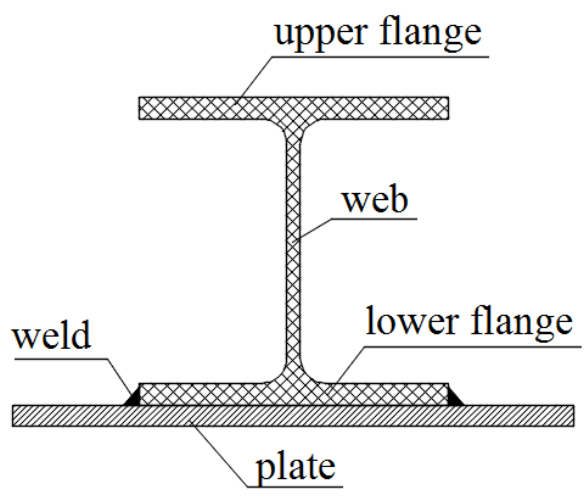

Fig. 1. a) Integrated Floor Beam (IFB). b) Shallow Floor Beam (SFB). 
a)

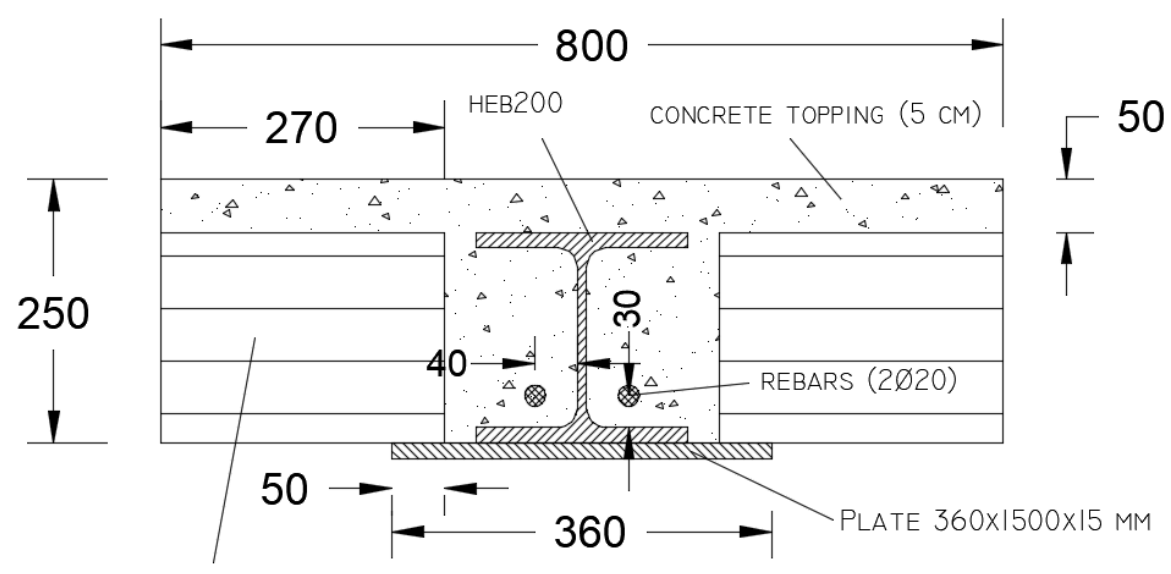

HOLLOW CORE SLAB (20 cM)

b)

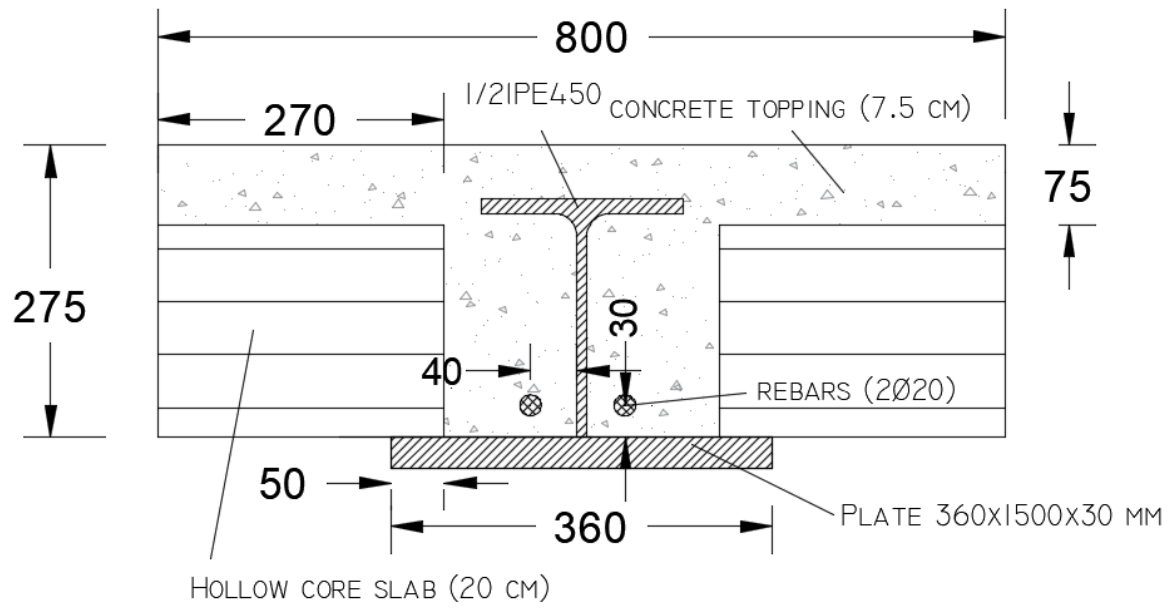

Fig. 2. a) Specimen A1 geometry. b) Specimen A3 geometry. 
Albero V, Serra E. Espinós A, Romero ML, Hospitaler A. Innovative solutions for enhancing the fire resistance of slim-

floor beams: Thermal experiments. Journal of Constructional Steel Research 2020; 165. https://doi.org/10.1016/j.jcsr.2019.105897

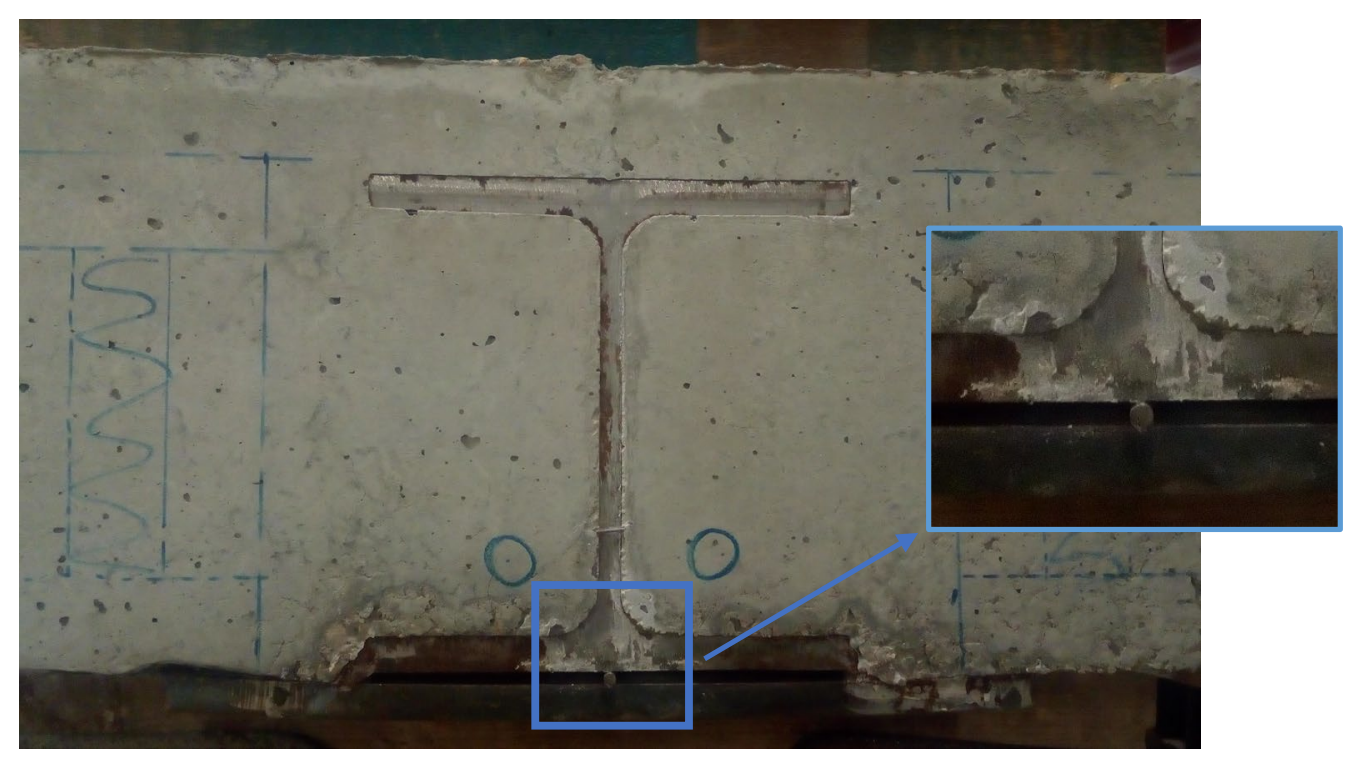

Fig. 3. Specimen A7 detail. Gap increased using wire $(1 \phi 5 \mathrm{~mm})$. 

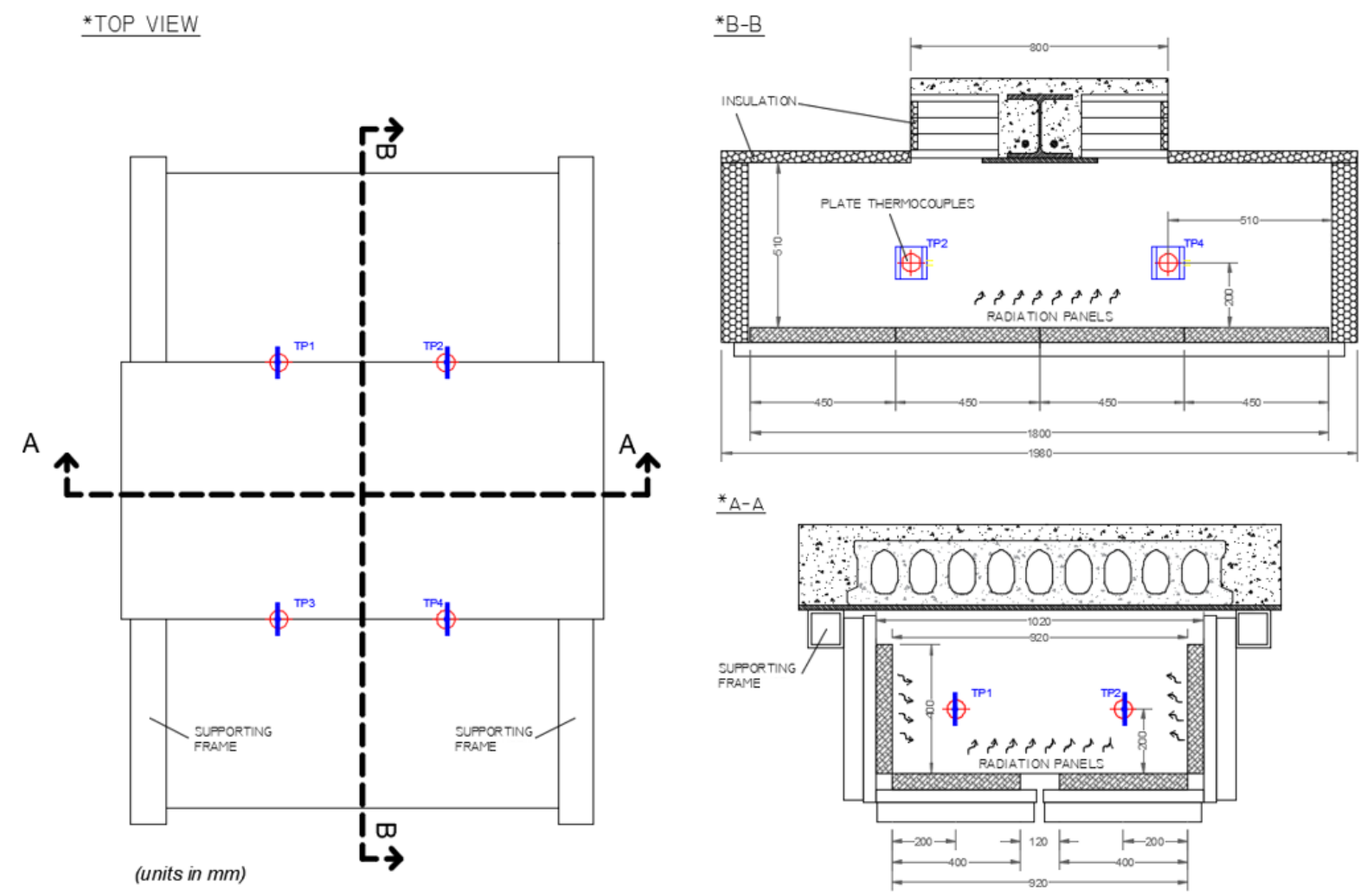

Fig. 4. Furnace layout. 
Albero V, Serra E. Espinós A, Romero ML, Hospitaler A. Innovative solutions for enhancing the fire resistance of slim-

floor beams: Thermal experiments. Journal of Constructional Steel Research 2020; 165. https://doi.org/10.1016/j.jcsr.2019.105897

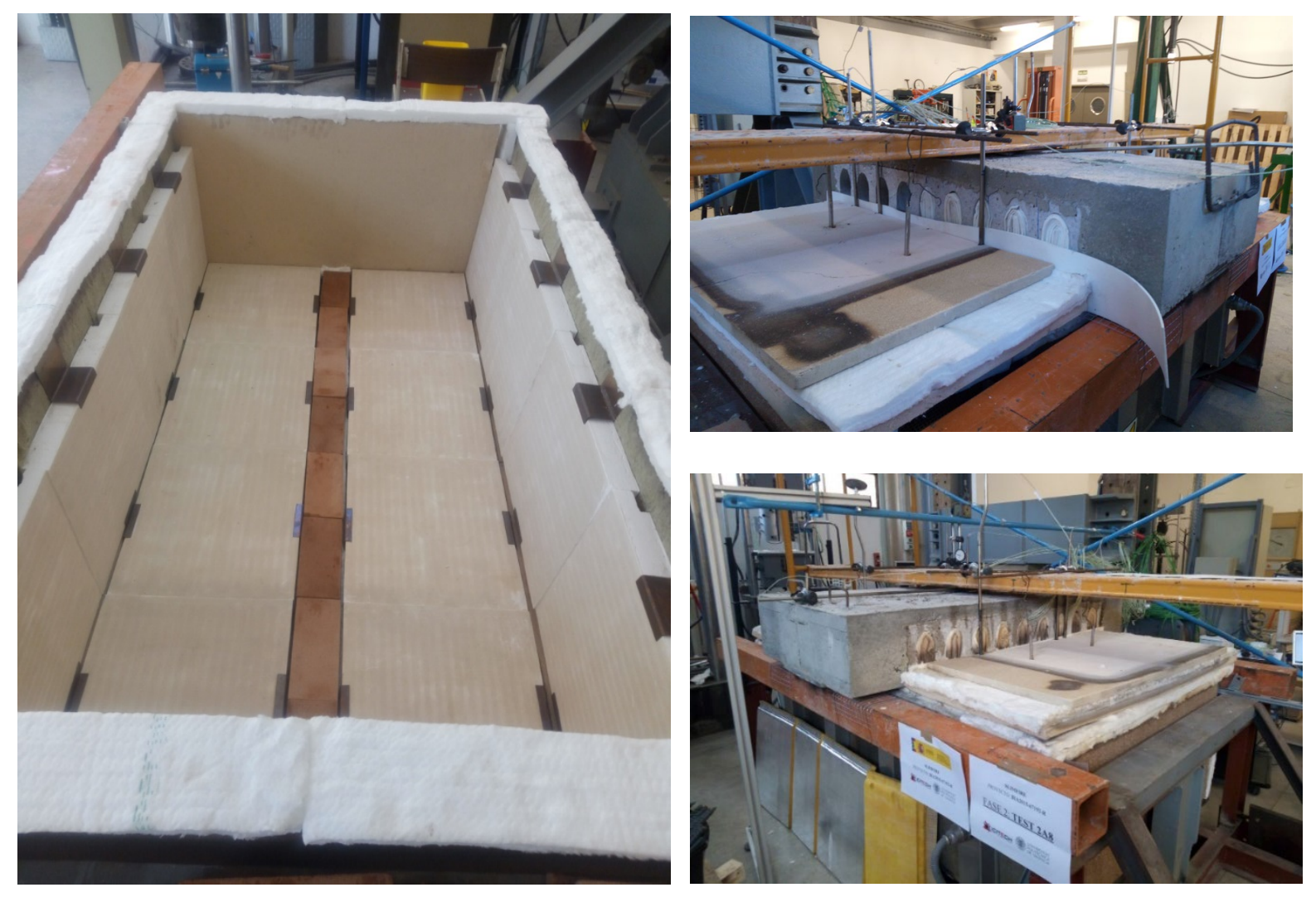

Fig. 5. Details of the furnace and test setup. 
a)

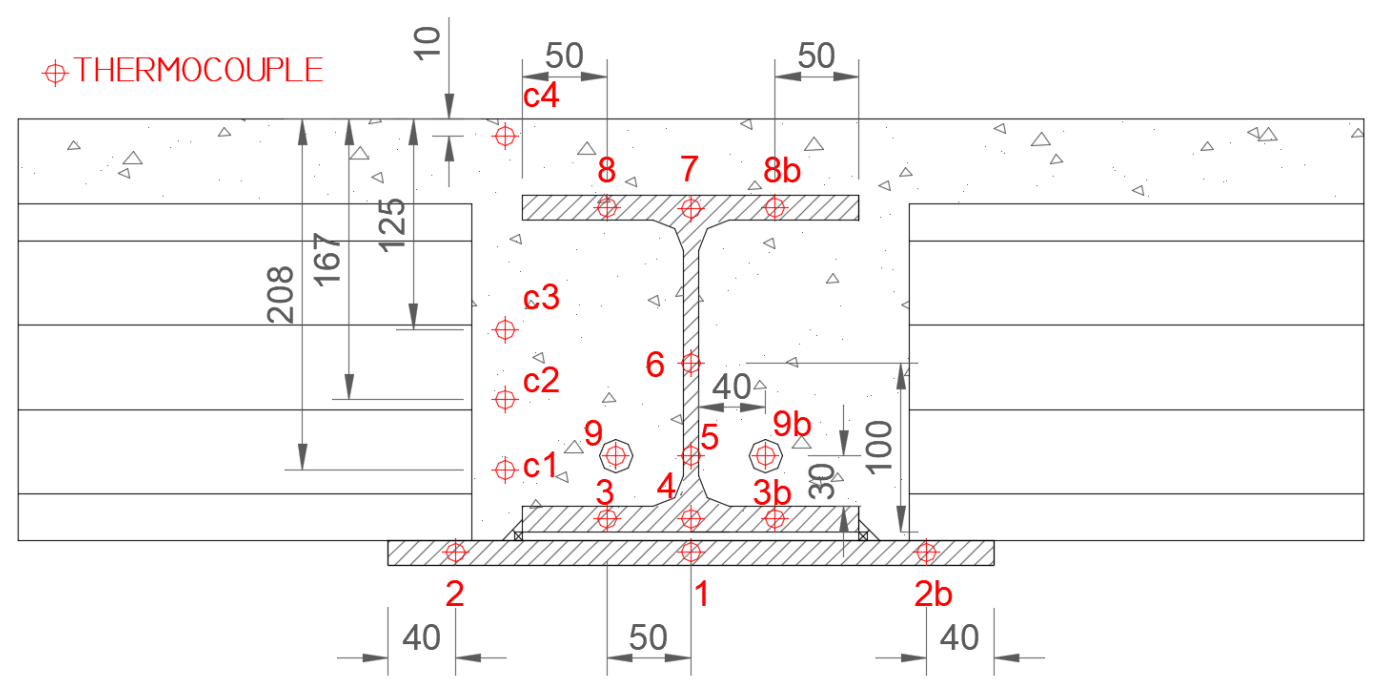

b)

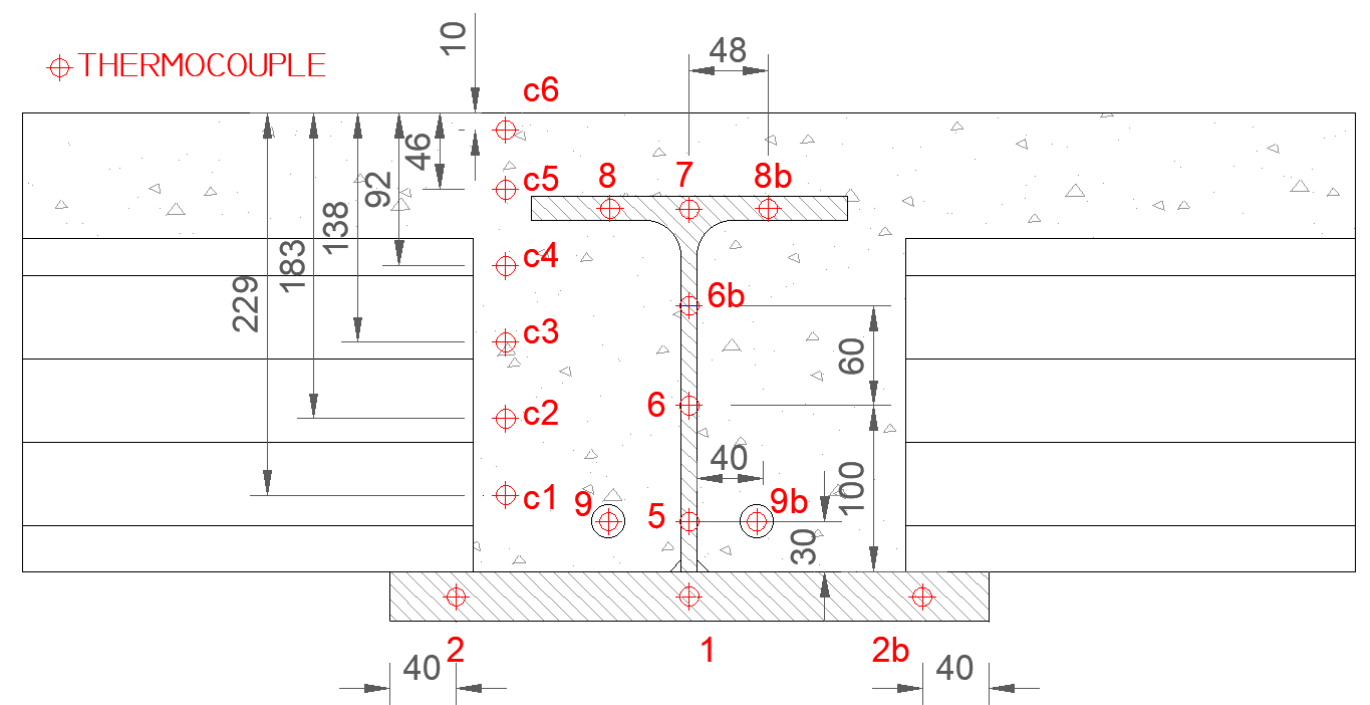

Fig. 6. Thermocouple distribution. a) Specimen A1, b) Specimen A3. 
Albero V, Serra E. Espinós A, Romero ML, Hospitaler A. Innovative solutions for enhancing the fire resistance of slim-

floor beams: Thermal experiments. Journal of Constructional Steel Research 2020; 165. https://doi.org/10.1016/j.jcsr.2019.105897

a) Test A1

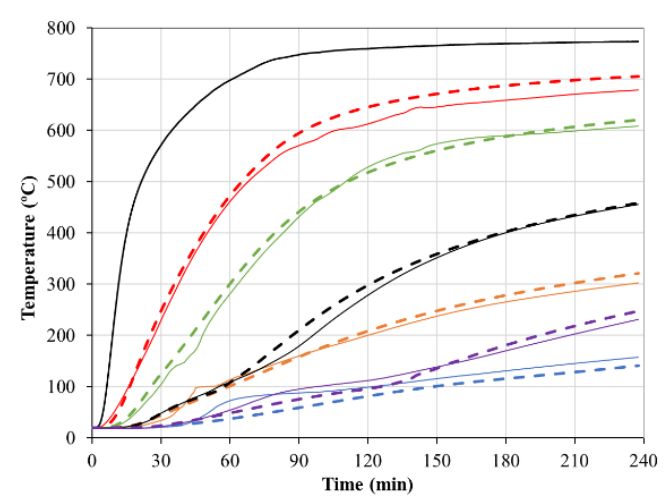

c) Test A4

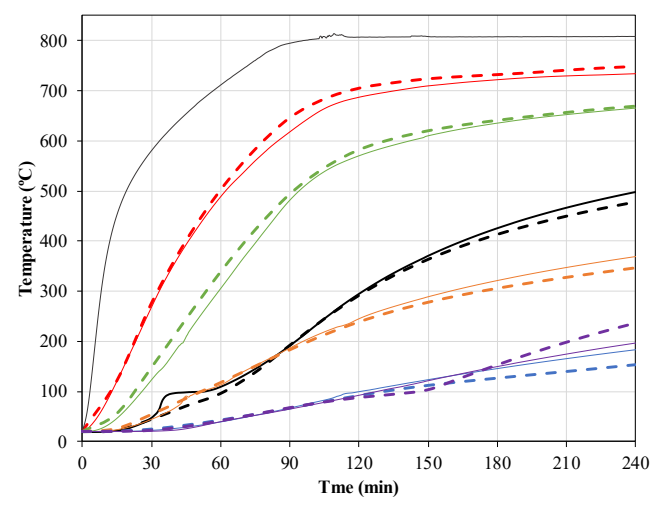

e) Test A6

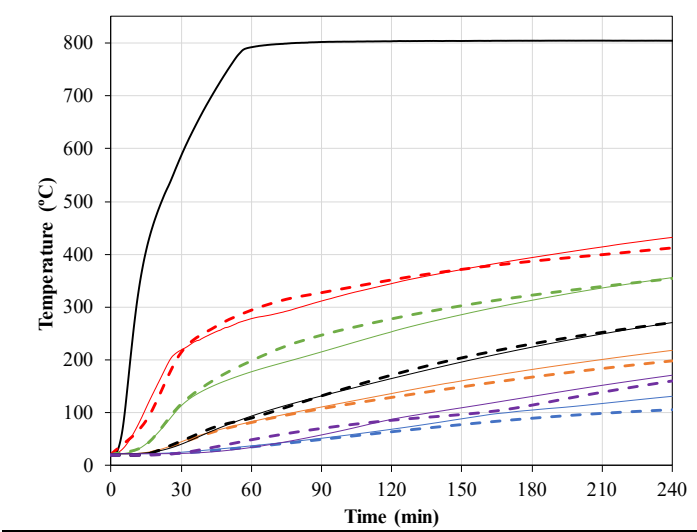

b) Test A2

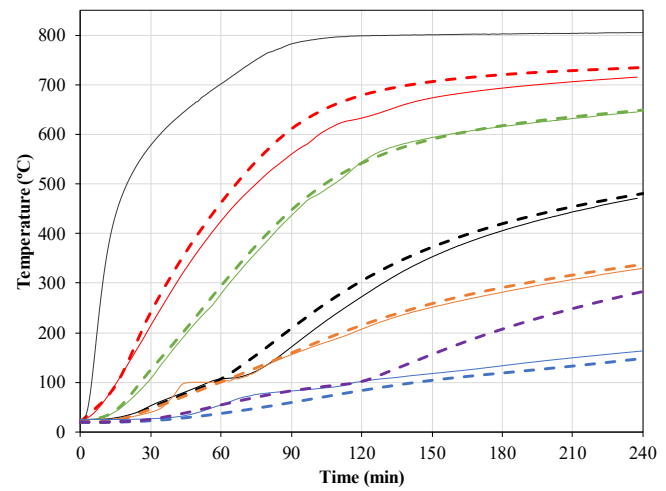

d) Test A5

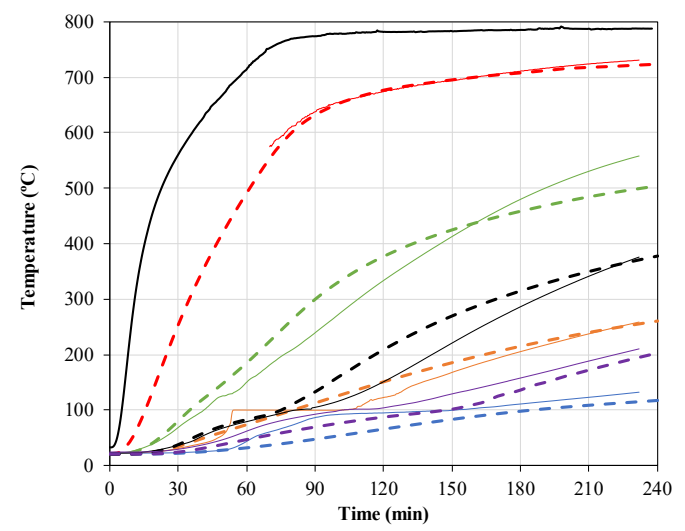

f) Test A7

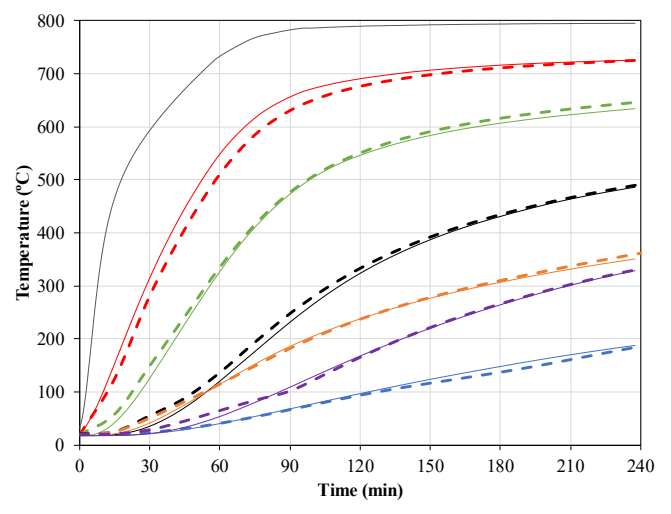

g) Test A3
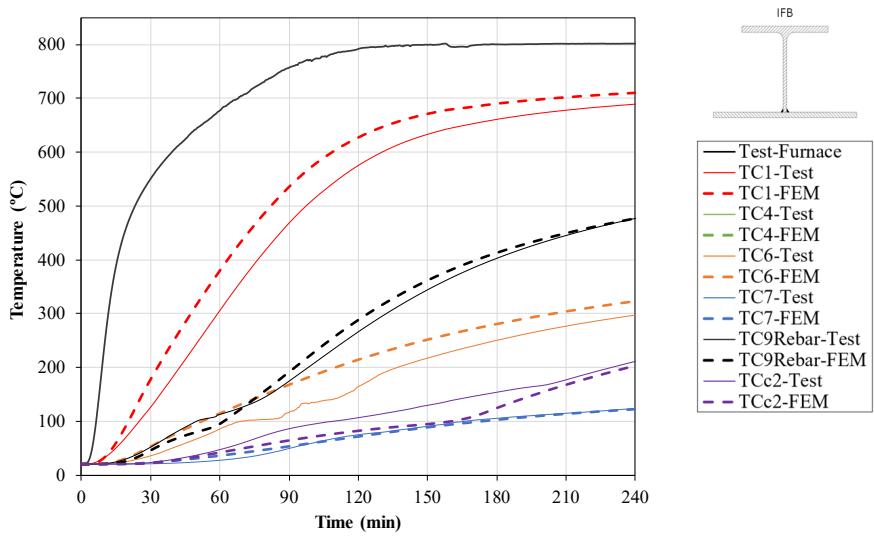

29

(C2020. This manuscript version is made available under the CC-BY- NC-ND 4.0 license https://creativecommons.org/licenses/by-nc$\mathrm{nd} / 4.0 /$ 
Albero V, Serra E. Espinós A, Romero ML, Hospitaler A. Innovative solutions for enhancing the fire resistance of slimfloor beams: Thermal experiments. Journal of Constructional Steel Research 2020; 165. https://doi.org/10.1016/j.jcsr.2019.105897

Fig. 7. Comparison between test and numerical results.

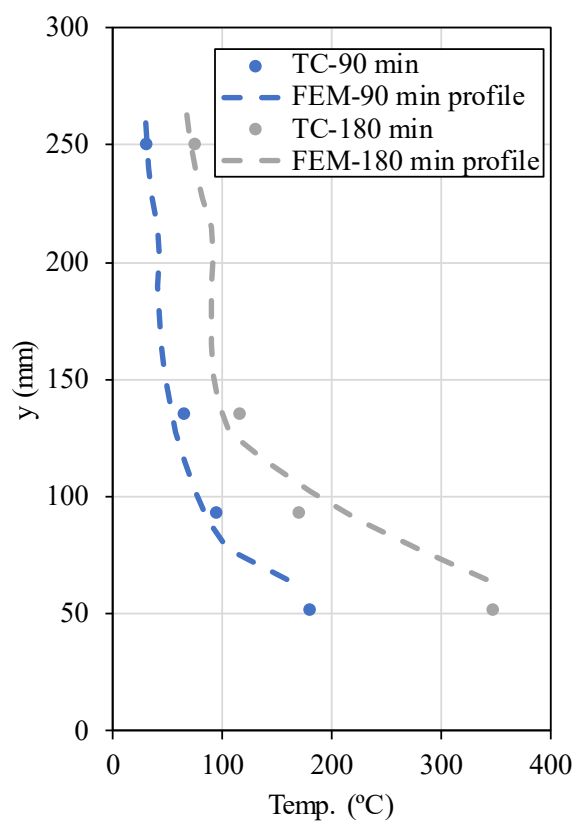

Fig. 8. Temperature distribution along concrete depth in test A1. 
Albero V, Serra E. Espinós A, Romero ML, Hospitaler A. Innovative solutions for enhancing the fire resistance of slim-

floor beams: Thermal experiments. Journal of Constructional Steel Research 2020; 165. https://doi.org/10.1016/j.jcsr.2019.105897

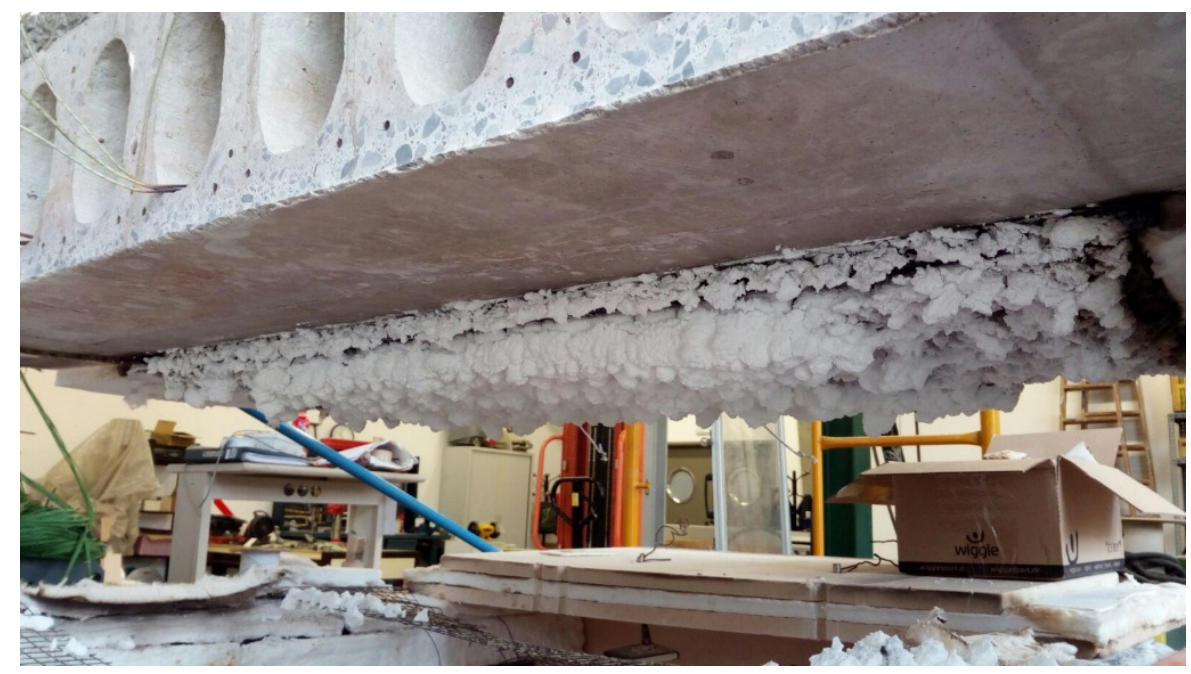

Fig. 9. View of A6 specimen from its bottom surface after fire exposure. 
Albero V, Serra E. Espinós A, Romero ML, Hospitaler A. Innovative solutions for enhancing the fire resistance of slim-

floor beams: Thermal experiments. Journal of Constructional Steel Research 2020; 165.

https://doi.org/10.1016/j.jcsr.2019.105897
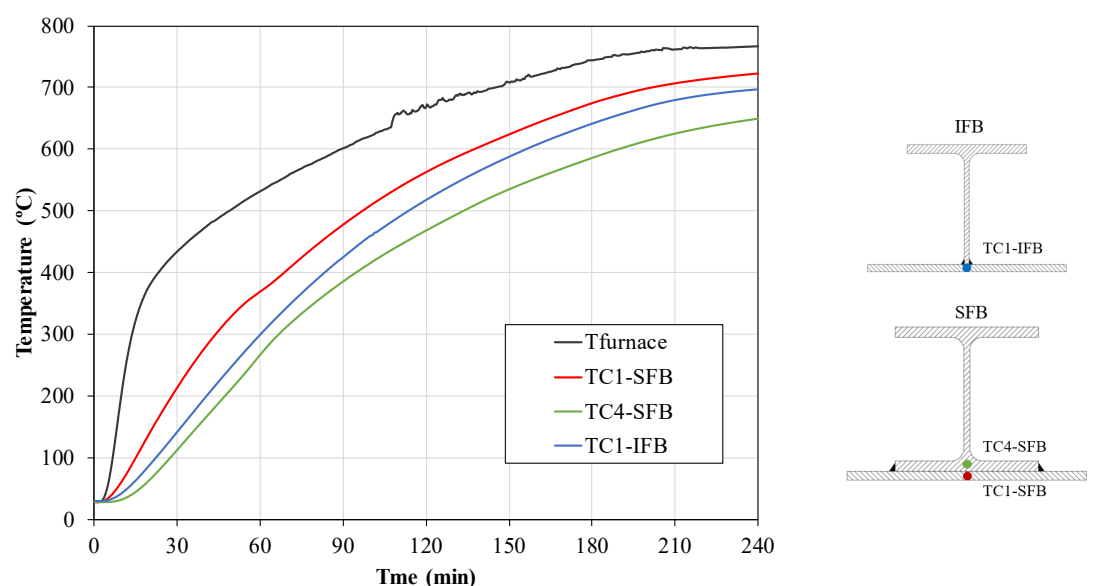

Fig. 10. Test A8 results.

(c)2020. This manuscript version is made available under the CC-BY- NC-ND 4.0 license https://creativecommons.org/licenses/by-nc$\mathrm{nd} / 4.0 /$ 
- - - Gap conductance: $250 \mathrm{~W} / \mathrm{m}^{2} \mathrm{~K}$

- - - Gap conductance: $100 \mathrm{~W} / \mathrm{m}^{2} \mathrm{~K}$

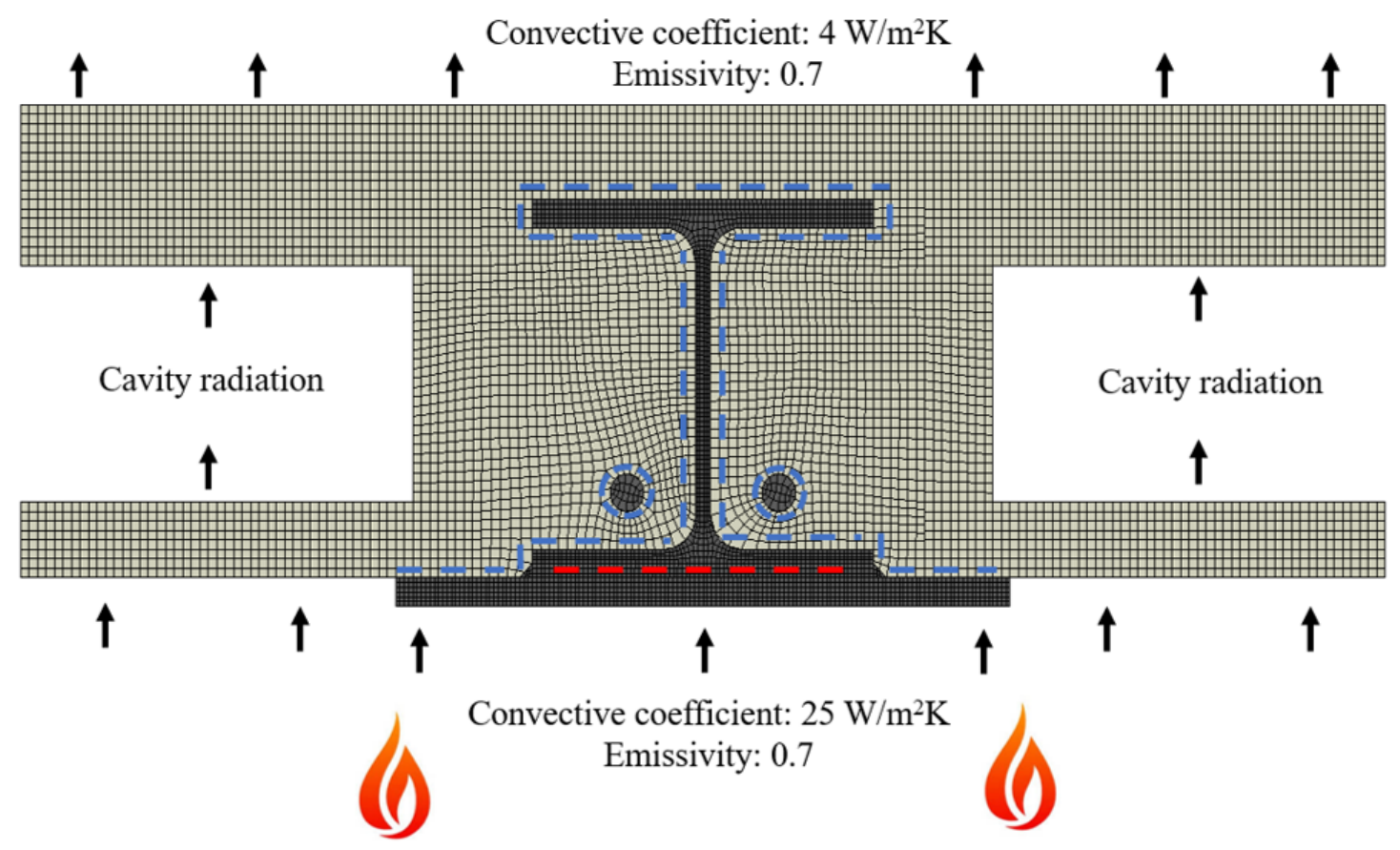

Fig. 11. FEM mesh and boundary conditions. 
Albero V, Serra E. Espinós A, Romero ML, Hospitaler A. Innovative solutions for enhancing the fire resistance of slim-

floor beams: Thermal experiments. Journal of Constructional Steel Research 2020; 165. https://doi.org/10.1016/j.jcsr.2019.105897
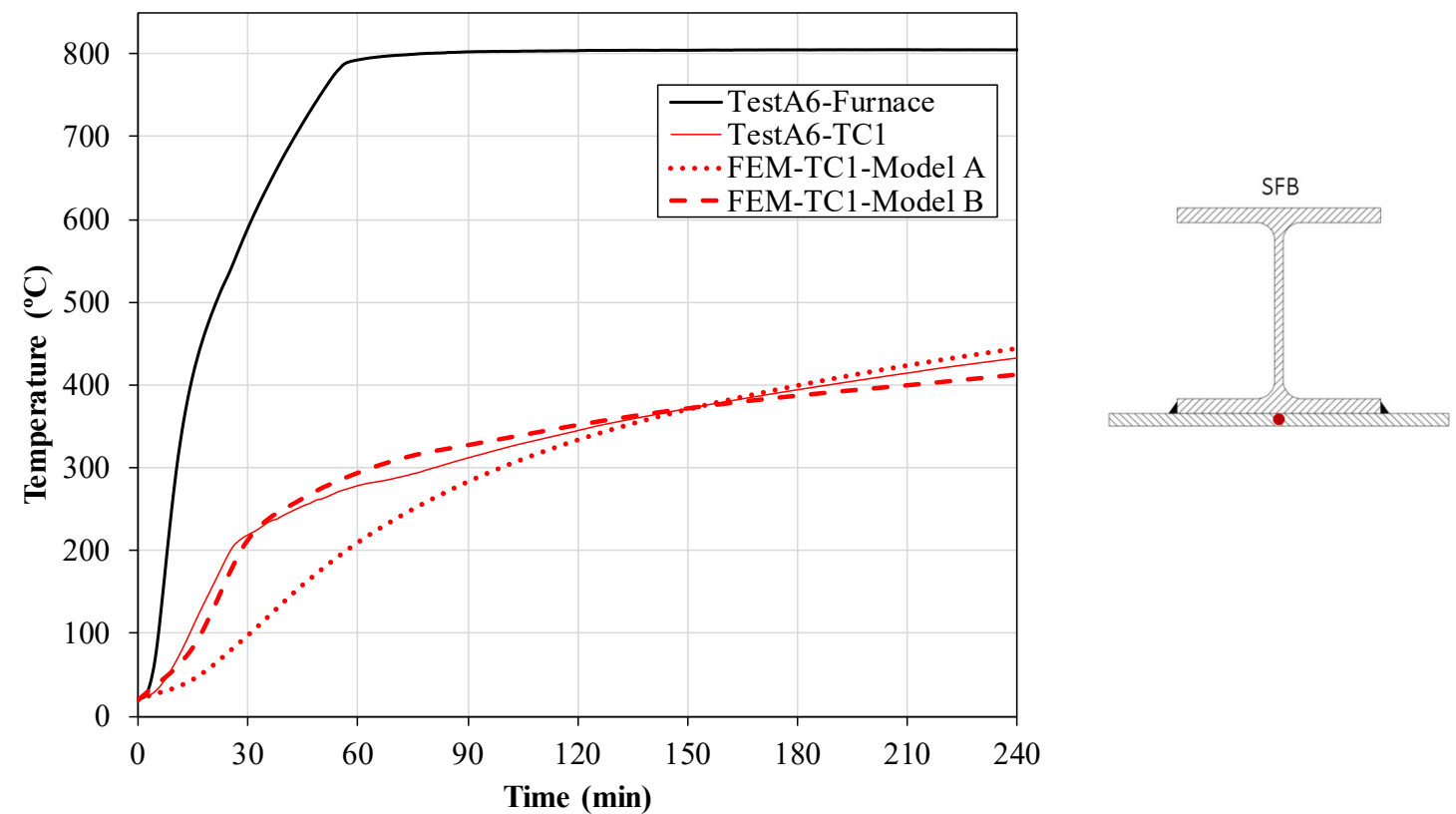

Fig. 12. Comparison of intumescent coating FEM modelling. 


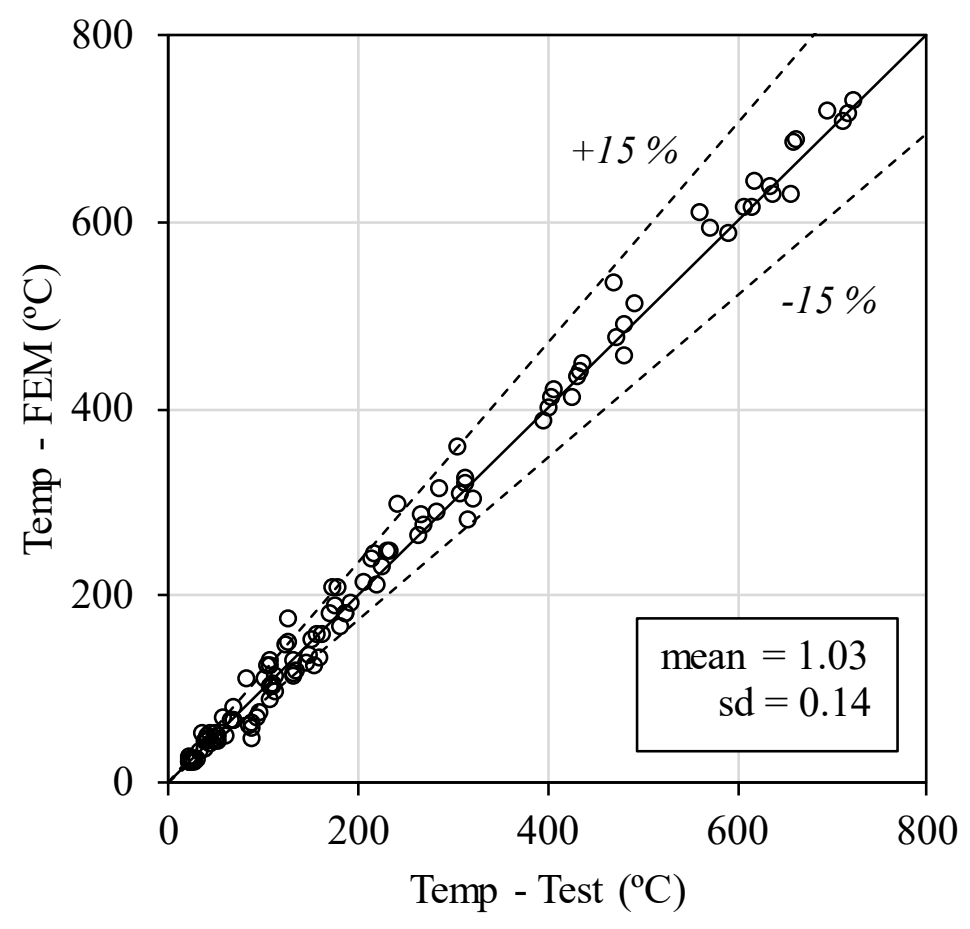

Fig. 13. Comparison of temperature predictions (FEM versus experimental results). 
Albero V, Serra E. Espinós A, Romero ML, Hospitaler A. Innovative solutions for enhancing the fire resistance of slim-

floor beams: Thermal experiments. Journal of Constructional Steel Research 2020; 165.

https://doi.org/10.1016/j.jcsr.2019.105897
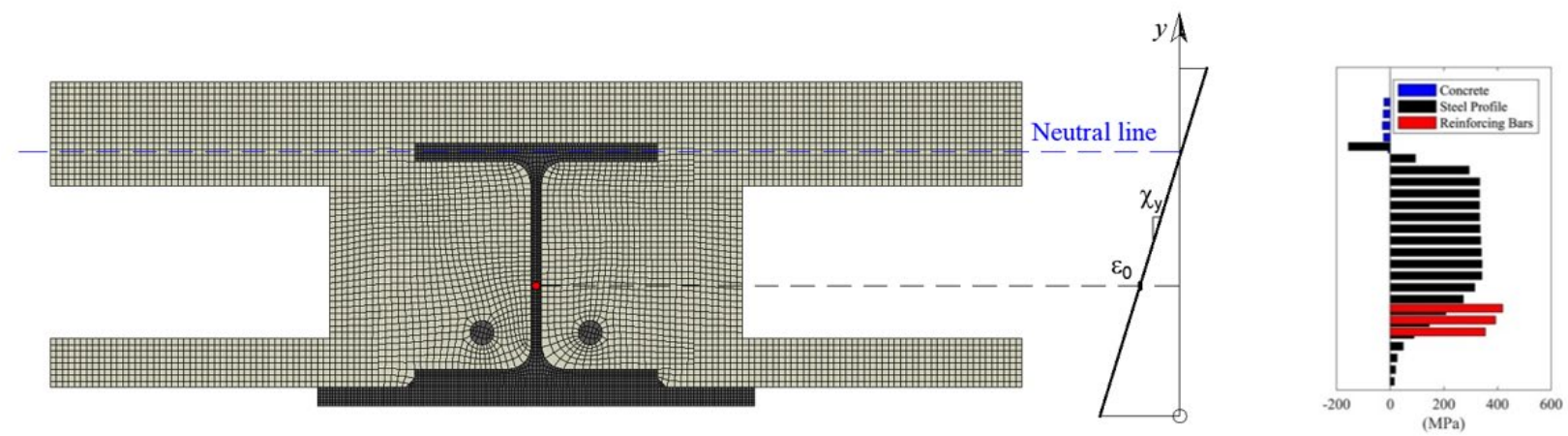

Fig. 14. Cross-section equilibrium diagram.

(c)2020. This manuscript version is made available under the CC-BY- NC-ND 4.0 license https://creativecommons.org/licenses/by-nc$\mathrm{nd} / 4.0 /$ 


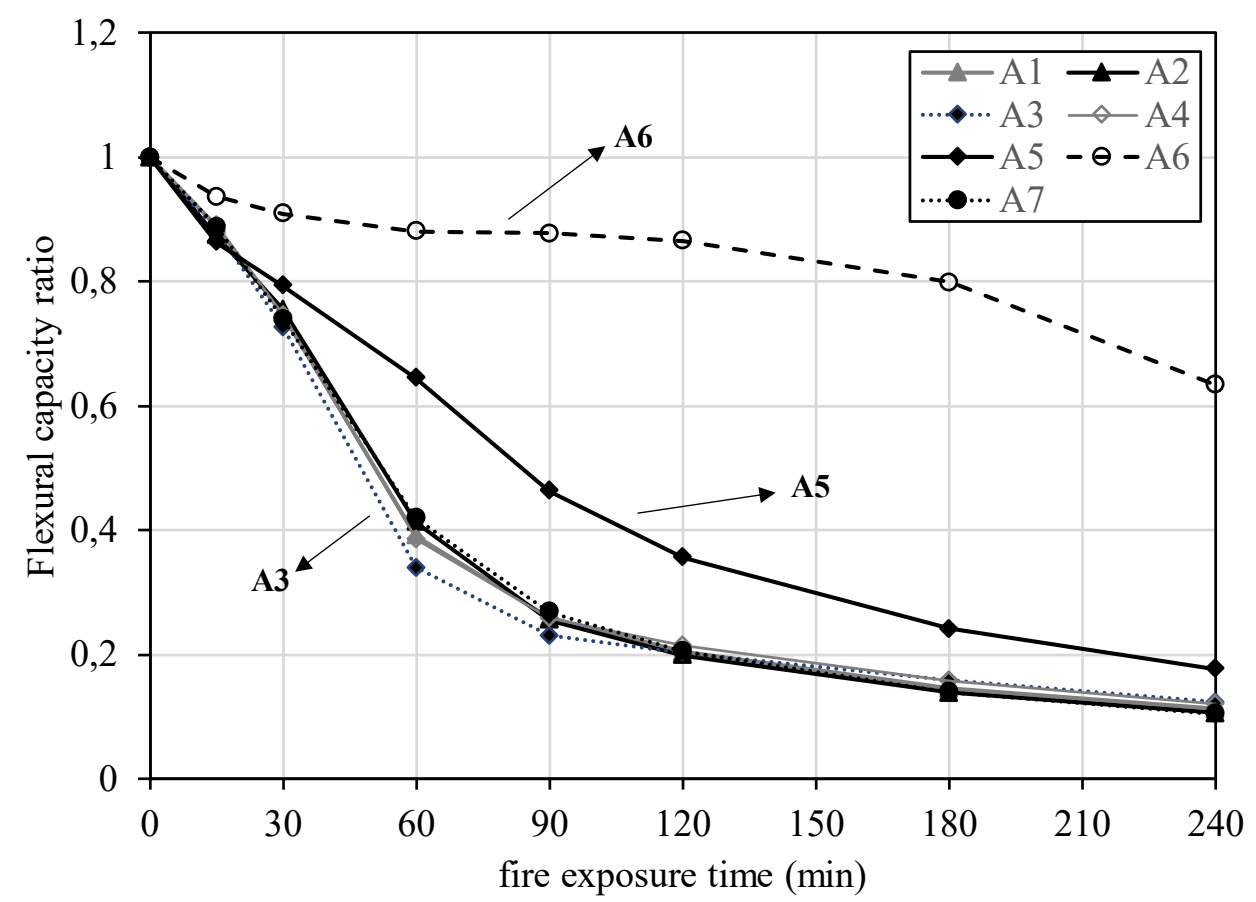

Fig. 15. Evolution of the flexural capacity ratio under ISO834 fire exposure (composite action). 
Table 1. Test specimens list.

\begin{tabular}{ccc}
\hline Group & ID & Description \\
\hline & A1 & SFB (HEB200 + Plate 15) + Normal Concrete + HCS20 \\
1 & A2 & SFB (HEB200 + Plate 20) + Normal Concrete + HCS20 \\
& A3 & IFB $(1 / 2$ IPE 450 + Plate 30) + Normal Concrete + HCS20 \\
\hline 2 & A4 & SFB (HEB200 + Plate 15) + Lightweight Concrete + HCS20 \\
\hline \multirow{3}{*}{3} & A5 & SFB (HEB200 + Plate 15 (Stainless steel $)+$ Normal Concrete + HCS20 \\
& A6 & SFB (HEB200 + Plate 15) + Normal Concrete + HCS20 + Intumescent coating \\
& A7 & SFB (HEB200 + Plate 15) + Normal Concrete + HCS20 + Gap increased \\
\hline 4 & A8 & SFB A1 + IFB A3 \\
\hline
\end{tabular}


Table 2. Experimental and numerical results. (Temperatures in ${ }^{\circ} \mathrm{C}$ )

\begin{tabular}{|c|c|c|c|c|c|c|c|}
\hline $\begin{array}{l}\text { Time } \\
(\mathrm{min})\end{array}$ & TF & $\begin{array}{c}\text { TC1 } \\
\text { exp/num }\end{array}$ & $\begin{array}{c}\text { TC4 } \\
\text { exp/num }\end{array}$ & $\begin{array}{c}\text { TC6 } \\
\text { exp/num }\end{array}$ & $\begin{array}{c}\text { TC7 } \\
\text { exp/num }\end{array}$ & $\begin{array}{c}\text { TC9 } \\
\text { exp/num }\end{array}$ & $\begin{array}{c}\text { TCc2 } \\
\text { exp/num }\end{array}$ \\
\hline & & \multicolumn{4}{|c|}{ (steel) } & (rebars) & (concrete) \\
\hline \multicolumn{8}{|c|}{ Test A1 } \\
\hline 30 & 571 & $229 / 247$ & $104 / 125$ & $37 / 44$ & $20 / 23$ & $48 / 48$ & $23 / 24$ \\
\hline 90 & 748 & $570 / 594$ & $432 / 441$ & $160 / 158$ & $87 / 59$ & $179 / 210$ & $95 / 76$ \\
\hline 180 & 770 & $659 / 687$ & $590 / 588$ & $265 / 287$ & $130 / 116$ & $400 / 402$ & $170 / 181$ \\
\hline \multicolumn{8}{|c|}{ Test A2 } \\
\hline 30 & 580 & $214 / 241$ & $107 / 126$ & $40 / 46$ & $27 / 23$ & $59 / 50$ & $* * / 25$ \\
\hline 90 & 784 & $560 / 611$ & $436 / 448$ & $156 / 159$ & $83 / 60$ & $171 / 209$ & $* * / 83$ \\
\hline 180 & 804 & $694 / 720$ & $616 / 618$ & $281 / 290$ & $134 / 119$ & $405 / 421$ & $* * / 207$ \\
\hline \multicolumn{8}{|c|}{ Test A3 } \\
\hline 30 & 551 & $126 / 176$ & - & $35 / 53$ & $20 / 23$ & $52 / 45$ & $23 / 22$ \\
\hline 90 & 757 & $468 / 535$ & - & $115 / 167$ & $49 / 53$ & $174 / 191$ & $86 / 64$ \\
\hline 180 & 800 & $661 / 690$ & - & $250 / 280$ & $106 / 102$ & $403 / 412$ & $154 / 125$ \\
\hline \multicolumn{8}{|c|}{ Test A4 } \\
\hline 30 & 582 & $268 / 275$ & $122 / 147$ & $44 / 54$ & $23 / 25$ & $48 / 45$ & $20 / 22$ \\
\hline 90 & 796 & $618 / 645$ & $481 / 492$ & $186 / 182$ & $67 / 67$ & $191 / 192$ & $64 / 67$ \\
\hline 180 & 809 & $722 / 732$ & $635 / 640$ & $321 / 305$ & $146 / 127$ & $425 / 413$ & $149 / 153$ \\
\hline \multicolumn{8}{|c|}{ Test A5 } \\
\hline 30 & 559 & $-/ 253$ & $69 / 80$ & $31 / 34$ & $23 / 22$ & $38 / 37$ & $29 / 24$ \\
\hline 90 & 774 & $638 / 632$ & $240 / 299$ & $100 / 112$ & $86 / 47$ & $106 / 132$ & $92 / 69$ \\
\hline 180 & 785 & $711 / 708$ & $479 / 458$ & $205 / 214$ & $111 / 98$ & $286 / 314$ & $158 / 135$ \\
\hline \multicolumn{8}{|c|}{ Test A6 } \\
\hline 30 & 587 & $219 / 213$ & $113 / 116$ & $44 / 43$ & $25 / 23$ & $40 / 47$ & $23 / 24$ \\
\hline 90 & 801 & $312 / 327$ & $215 / 246$ & $110 / 107$ & $52 / 49$ & $132 / 132$ & $57 / 71$ \\
\hline 180 & 804 & $394 / 387$ & $313 / 322$ & $181 / 167$ & $105 / 90$ & $224 / 231$ & $131 / 115$ \\
\hline \multicolumn{8}{|c|}{ Test A7 } \\
\hline 30 & 596 & $315 / 282$ & $126 / 150$ & $41 / 51$ & $20 / 24$ & $35 / 54$ & $21 / 28$ \\
\hline 90 & 784 & $657 / 631$ & $473 / 477$ & $185 / 182$ & $68 / 67$ & $232 / 247$ & $109 / 102$ \\
\hline 180 & 795 & $717 / 717$ & $607 / 616$ & $306 / 310$ & $148 / 138$ & $431 / 434$ & $264 / 266$ \\
\hline \multicolumn{8}{|c|}{ Test A8. Specimen SFB } \\
\hline 30 & 434 & $215 /-$ & $114 /-$ & - & - & - & - \\
\hline 90 & 601 & $479 /-$ & $386 /-$ & - & - & - & - \\
\hline 180 & 743 & $675 /-$ & $589 /-$ & - & - & - & - \\
\hline \multicolumn{8}{|c|}{ Test A8. Specimen IFB } \\
\hline 30 & 434 & $142 /-$ & - & - & - & - & - \\
\hline 90 & 601 & $424 /-$ & - & - & - & - & - \\
\hline 180 & 743 & $640 /-$ & - & - & - & - & - \\
\hline
\end{tabular}


Table 3. Plastic bending resistance under ISO834 fire exposure (composite action).

\begin{tabular}{|c|c|c|c|c|c|c|c|c|c|c|c|c|c|c|}
\hline \multirow{2}{*}{$\begin{array}{l}\text { fire exposure time } \\
\qquad(\mathrm{min})\end{array}$} & \multicolumn{2}{|c|}{ A1 } & \multicolumn{2}{|c|}{ A2 } & \multicolumn{2}{|c|}{ A3 } & \multicolumn{2}{|c|}{ A4 } & \multicolumn{2}{|c|}{ A5 } & \multicolumn{2}{|c|}{ A6 } & \multicolumn{2}{|c|}{ A7 } \\
\hline & $\begin{array}{c}\mathrm{M}_{\mathrm{pl}, \mathrm{Rd}, \theta} \\
(\mathrm{m} \cdot \mathrm{kN})\end{array}$ & $\begin{array}{c}\mathrm{NL} \\
(\mathrm{mm})\end{array}$ & $\begin{array}{c}\mathrm{M}_{\mathrm{pl}, \mathrm{Rd}, \theta} \\
(\mathrm{m} \cdot \mathrm{kN})\end{array}$ & $\begin{array}{c}\mathrm{NL} \\
(\mathrm{mm})\end{array}$ & $\begin{array}{c}\mathrm{M}_{\mathrm{pl}, \mathrm{Rd}, \theta} \\
(\mathrm{m} \cdot \mathrm{kN})\end{array}$ & $\begin{array}{c}\mathrm{NL} \\
(\mathrm{mm})\end{array}$ & $\begin{array}{c}\mathrm{M}_{\mathrm{pl}, \mathrm{Rd}, \theta} \\
(\mathrm{m} \cdot \mathrm{kN})\end{array}$ & $\begin{array}{c}\mathrm{NL} \\
(\mathrm{mm})\end{array}$ & $\begin{array}{c}\mathrm{M}_{\mathrm{pl}, \mathrm{Rd}, \theta} \\
(\mathrm{m} \cdot \mathrm{kN})\end{array}$ & $\begin{array}{c}\mathrm{NL} \\
(\mathrm{mm})\end{array}$ & $\begin{array}{c}\mathrm{M}_{\mathrm{pl}, \mathrm{Rd}, \theta} \\
(\mathrm{m} \cdot \mathrm{kN})\end{array}$ & $\begin{array}{c}\mathrm{NL} \\
(\mathrm{mm})\end{array}$ & $\begin{array}{c}\mathrm{M}_{\mathrm{pl}, \mathrm{Rd}, \theta} \\
(\mathrm{m} \cdot \mathrm{kN})\end{array}$ & $\begin{array}{c}\mathrm{NL} \\
(\mathrm{mm})\end{array}$ \\
\hline 0 & 656,1 & 116 & 715,6 & 87 & 910,2 & 116 & 656,1 & 116 & 652,1 & 119 & 656,1 & 116 & 657,2 & 117 \\
\hline 15 & 583,2 & 140 & 625,8 & 119 & 802,3 & 162 & 583,2 & 140 & 562,5 & 156 & 614,0 & 139 & 584,0 & 143 \\
\hline 30 & 490,0 & 176 & 539,9 & 157 & 661,5 & 195 & 488,7 & 169 & 517,2 & 169 & 596,1 & 146 & 486,4 & 173 \\
\hline 60 & 256,6 & 205 & 295,8 & 203 & 309,6 & 244 & 252,7 & 205 & 420,6 & 188 & 578,0 & 153 & 275,5 & 208 \\
\hline 90 & 170,0 & 212 & 183,2 & 211 & 209,3 & 248 & 169,1 & 211 & 302,1 & 203 & 575,4 & 153 & 176,3 & 215 \\
\hline 120 & 133,9 & 216 & 142,2 & 215 & 185,0 & 253 & 140,2 & 214 & 232,4 & 209 & 567,4 & 161 & 134,5 & 220 \\
\hline 180 & 95,3 & 221 & 99,4 & 221 & 143,8 & 256 & 102,8 & 218 & 157,2 & 216 & 524,0 & 174 & 91,6 & 224 \\
\hline 240 & 73,4 & 225 & 75,3 & 224 & 112,3 & 258 & 79,7 & 222 & 115,2 & 220 & 415,6 & 198 & 69,0 & 228 \\
\hline
\end{tabular}


Table 4. Plastic bending resistance under ISO834 fire exposure (non-composite action).

\begin{tabular}{|c|c|c|c|c|c|c|c|c|c|c|c|c|c|c|}
\hline \multirow{2}{*}{$\begin{array}{l}\text { fire exposure time } \\
\qquad(\mathrm{min})\end{array}$} & \multicolumn{2}{|c|}{ A1 } & \multicolumn{2}{|c|}{ A2 } & \multicolumn{2}{|c|}{ A3 } & \multicolumn{2}{|c|}{ A4 } & \multicolumn{2}{|c|}{ A5 } & \multicolumn{2}{|c|}{ A6 } & \multicolumn{2}{|c|}{ A7 } \\
\hline & $\begin{array}{r}\mathrm{M}_{\mathrm{pl}, \mathrm{Rd}, \theta} \\
(\mathrm{m} \cdot \mathrm{kN})\end{array}$ & $\begin{array}{c}\mathrm{NL} \\
(\mathrm{mm})\end{array}$ & $\begin{array}{r}\mathrm{M}_{\mathrm{pl}, \mathrm{Rd}, \theta} \\
(\mathrm{m} \cdot \mathrm{kN})\end{array}$ & $\begin{array}{c}\text { NL } \\
(\mathrm{mm})\end{array}$ & $\begin{array}{r}\mathrm{M}_{\mathrm{pl}, \mathrm{Rd}, \theta} \\
(\mathrm{m} \cdot \mathrm{kN})\end{array}$ & $\begin{array}{c}\mathrm{NL} \\
(\mathrm{mm})\end{array}$ & $\begin{array}{r}\mathrm{M}_{\mathrm{pl}, \mathrm{Rd}, \theta} \\
(\mathrm{m} \cdot \mathrm{kN})\end{array}$ & $\begin{array}{c}\mathrm{NL} \\
(\mathrm{mm})\end{array}$ & $\begin{array}{c}\mathrm{M}_{\mathrm{pl}, \mathrm{Rd}, \theta} \\
(\mathrm{m} \cdot \mathrm{kN})\end{array}$ & $\begin{array}{c}\mathrm{NL} \\
(\mathrm{mm})\end{array}$ & $\begin{array}{r}\mathrm{M}_{\mathrm{pl}, \mathrm{Rd}, \theta} \\
(\mathrm{m} \cdot \mathrm{kN})\end{array}$ & $\begin{array}{c}\mathrm{NL} \\
(\mathrm{mm})\end{array}$ & $\begin{array}{c}\mathrm{M}_{\mathrm{pl}, \mathrm{Rd}, \theta} \\
(\mathrm{m} \cdot \mathrm{kN})\end{array}$ & $\begin{array}{c}\mathrm{NL} \\
(\mathrm{mm})\end{array}$ \\
\hline 0 & 359,4 & 26 & 376,1 & 21 & 435,0 & 25 & 359,4 & 26 & 360,2 & 26 & 359,4 & 26 & 367,6 & 30 \\
\hline 15 & 350,7 & 37 & 366,2 & 31 & 426,6 & 40 & 350,6 & 37 & 344,7 & 37 & 354,8 & 33 & 358,0 & 40 \\
\hline 30 & 324,8 & 63 & 346,5 & 52 & 400,0 & 62 & 323,5 & 62 & 334,7 & 55 & 353,0 & 36 & 327,0 & 65 \\
\hline 60 & 208,1 & 143 & 236,8 & 125 & 251,0 & 167 & 205,6 & 145 & 302,4 & 77 & 350,7 & 41 & 225,7 & 137 \\
\hline 90 & 137,7 & 199 & 150,4 & 197 & 177,1 & 224 & 139,5 & 199 & 240,7 & 123 & 349,4 & 44 & 148,3 & 203 \\
\hline 120 & 101,9 & 204 & 109,9 & 204 & 152,1 & 238 & 108,3 & 203 & 192,7 & 162 & 347,7 & 47 & 107,2 & 209 \\
\hline 180 & 64,4 & 209 & 68,3 & 209 & 111,3 & 244 & 71,8 & 207 & 126,0 & 203 & 336,6 & 62 & 65,2 & 214 \\
\hline 240 & 43,7 & 213 & 45,7 & 213 & 80,8 & 247 & 49,5 & 210 & 84,5 & 208 & 300,1 & 87 & 43,8 & 218 \\
\hline
\end{tabular}


Albero V, Serra E. Espinós A, Romero ML, Hospitaler A. Innovative solutions for enhancing the fire resistance of slimfloor beams: Thermal experiments. Journal of Constructional Steel Research 2020; 165. https://doi.org/10.1016/j.jcsr.2019.105897 